\title{
Carbon footprint of plastic from biomass and recycled feedstock: methodological insights
}

\author{
Davide Tonini $^{1}$ (1) $\cdot$ Dieuwertje Schrijvers $^{2} \cdot$ Simone Nessi $^{1,3} \cdot$ Pelayo Garcia-Gutierrez ${ }^{1} \cdot$ Jacopo Giuntoli $^{3}$
}

Received: 24 August 2020 / Accepted: 2 December 2020 / Published online: 21 January 2021

(c) The Author(s) 2021

\begin{abstract}
Purpose A circular (bio)economy is sustained through use of secondary raw material and biomass feedstock. In life cycle assessment (LCA), the approach applied to address the impact of these feedstocks is often unclear, in respect to both handling of the recycled content and End-of-Life recyclability and disposal. Further, the modelling approach adopted to account for land use change (LUC) and biogenic C effects is crucial to defining the impact of biobased commodities on global warming. Method We depart from state-of-the-art approaches proposed in literature and apply them to the case of non-biodegradable plastic products manufactured from alternative feedstock, focusing on selected polymers that can be made entirely from secondary raw material or biomass. We focus on global warming and the differences incurred by recycled content, recyclability, LUC, and carbon dynamics (effects of delayed emission of fossil C and temporary storage of biogenic C). To address the recycled content and recyclability, three formulas recently proposed are compared and discussed. Temporary storage of biogenic $\mathrm{C}$ is handled applying methods for dynamic accounting. LUC impacts are addressed by applying and comparing a biophysical, global equilibrium and a normative-based approach. These methods are applied to two case studies (rigid plastic for packaging and automotive applications) involving eight polymers.

Results and discussion Drawing upon the results, secondary raw material is the feedstock with the lowest global warming impact overall. The results for biobased polymers, while promising in some cases (polybutylene succinate), are significantly affected by the formulas proposed to handle the recycled content and recyclability. We observe that some of the proposed formulas in their current form do not fully capture the effects associated with the biogenic nature of the material when this undergoes recycling and substitutes fossil materials. Furthermore, the way in which the recycled content is modelled is important for wastes already in-use. LUC factors derived with models providing a combined direct and indirect impact contribute with $15-30 \%$ of the overall life cycle impact, which in magnitude is comparable to the savings from temporary storage of biogenic $\mathrm{C}$, when included.

Conclusion End-of-Life formulas can be improved by addition of corrective terms accounting for the relative difference in disposal impacts between the recycled and market-substituted product. This affects the assessment of biobased materials. Inclusion of LUCs effects using economic/biophysical models in addition to (direct) LUC already embedded in commercial datasets may result in double-counting and should be done carefully. Dynamic assessment allows for detailed modelling of the carbon cycle, providing useful insights into the impact associated with biogenic $\mathrm{C}$ storage.
\end{abstract}

Keywords Bioplastic $\cdot$ Secondary raw material $\cdot$ Biogenic carbon $\cdot$ End-of-Life $\cdot$ LUC $\cdot$ Dynamic LCA $\cdot$ Recycling

\section{Introduction}

Communicated by Enrico Benetto.

Davide Tonini

davide.tonini@ec.europa.eu

1 European Commission Joint Research Centre, Seville, Spain

2 Institute of Molecular Sciences (ISM), University of Bordeaux, CNRS, Bordeaux INP, UMR 5255, 33400 Talence, France

3 European Commission Joint Research Centre, Ispra, Italy
More than $90 \%$ of plastic today is produced from fossil feedstock generating approximately 400 million tonnes of greenhouse gas (GHG) emissions per year globally (World Economic Forum and Foundation, 2016); estimates for 2012). According to the same source, by 2050 plastic production might account for $20 \%$ of global oil consumption and $15 \%$ of the global annual carbon emissions. The use of alternative feedstock for plastic production is therefore an important 
avenue to reduce fossil fuels use and mitigating GHG emissions. In this respect, recycled plastic (secondary raw materials) and various biomass materials represent promising alternatives. On the one hand, exploiting secondary raw material as feedstock for plastic products is expected to reduce disposal impacts and increase the circularity of the economy; on the other hand, recycling efforts and recyclate quality are often the limiting factors to ensuring lower environmental impacts and market competitiveness compared to conventional production paths. As for biomass, while considered a valuable carbon source being renewable, versatile, and storable, several concerns persist in relation to the impacts of sourcing and subsequent processing. This is especially relevant with respect to the impact on global warming, as learned from the extensive literature on bioenergy (Agostini et al. 2020). To quantify the impacts associated with plastic production from secondary raw material and biomass, life cycle assessment (LCA) is typically the method of choice.

The point of departure of our analysis is a literature screening of 171 LCA studies addressing plastics produced from recycled plastics and biomass conducted by Nessi et al. (2019). Nessi et al. highlight that the key methodological aspects in which the studies differ are the handling of (i) inputfeedstock (e.g. when biomass residues or recycled material were used), (ii) biogenic carbon (uptake/release, temporary storage and End-of-Life storage of carbon), (iii) impacts of land use changes (direct and indirect, i.e. dLUC and iLUC), and (iv) multifunctionality (approaches used in the datasets to handle co-products). Modelling of the process feedstock is particularly important for the case of recycled material or waste biomass. In this respect, the impacts associated with the feedstock are typically considered in one of these three ways: (i) the feedstock is considered burden-free, (ii) the burdens are modelled via economic or mass allocation, and (iii) burdens are calculated via substitution (Nessi et al. 2019). While the first option can be seen as a cut-off, the allocation method attributes a share of the burden from the production of the main crop/ virgin plastic to the residual material, and substitution provides a credit or burden based on displaced uses or avoided treatment of the waste. Similarly, modelling the End-of-Life EoL of plastics involves handling the effects of either landfilling, recycling, or energy recovery, with displacement of virgin material and resources requiring consideration for the latter two alternatives. This is tackled in very different manners across LCA studies, often inconsistently, as illustrated in Allacker et al. $(2014,2017)$. In this context, rather comprehensive modelling formulas encompassing both the feedstock and End-of-Life (EoL) have been recently proposed by Allacker et al. (2017), Schrijvers et al. (2016, 2020a, b) and Zampori et al. (2016). A more detailed description is provided later, but in essence these formulas strive to provide a consistent framework with which to model upstream and downstream effects associated with input-feedstock and recyclability at
EoL. However, they have not yet been applied to concrete bioplastic case studies, as far as the authors are aware.

Nessi et al. (2017) also show that the modelling of biogenic carbon varies significantly among the reviewed studies and that different approaches are proposed in existing standards for the biogenic carbon accounting of bioproducts. CEN (2015) (Bio-based products;life cycle assessment) instructs the user to calculate GHG emissions dynamically to capture the time-dependent impact of the full biogenic carbon cycle on the climate. Similarly, BSI (2011) ("specification for the assessment of the life cycle greenhouse gas emissions of goods and services") instructs the user to account for the portion of biogenic carbon not released within the 100-year time horizon of the assessment and thus considered to be permanently stored. This is not the case in ISO (2013), BSI (2012) (PAS 2050 for horticultural products) and European Commission (2013), which suggest assigning a global warming potential (GWP) equal to zero to $\mathrm{CO}_{2}$ biogenic uptake and release. To capture the GHG effects of biogenic carbon storage in the technosphere as well as of its delayed emission, advanced dynamic modelling has been proposed (notably Cherubini et al. 2011; Cherubini et al. 2016; Guest et al. 2013; Levasseur et al. 2016). However, the authors are aware of only one LCA study in which delayed GHG emissions were modelled dynamically for bioplastics (Rossi et al. 2015). It should be further noticed that the way biogenic $\mathrm{C}$ is handled also affects the $\mathrm{C}$-footprint of bioproducts whenever recycling is applied at the EoL, as illustrated in Finkbeiner et al. (2012). The authors particularly stressed that savings from biogenic $\mathrm{C}$ embedded in the product and recycled should be handled consistently to the remaining GHG emissions, e.g. in respect to partition between subsequent life cycles.

Furthermore, similarly to what is found with many bioenergy pathways, the inclusion of LUC impacts may reveal that the global warming impact of biosystems is worse than that of their fossil counterpart. While no broad consensus exists on which LUC model is preferable, it has become clear that these impacts should be included in order to provide a comprehensive view of the impact of bio-based commodities on the climate; nonetheless, only a few of the LCA studies reviewed by Nessi et al. (2019) included the iLUC GW contribution. Lastly, handling of multifunctionality due to co-production is a recurrent issue in LCA. European Commission (2013) and ISO (2006) are aligned in suggesting a hierarchy where subdivision and system expansion are preferred over allocation. Nevertheless, studies apply different criteria and results are therefore not always comparable as shown in a recent meta-analysis by Walker and Rothman (2020). Schrijvers et al. (2020a, b) demonstrated how the modelling of multifunctionality is dependent on the research question at hand. For example, system expansion is applied to answer the question "Is the production of Product $\mathrm{X}$ and Product $\mathrm{Y}$ via 
a co-producing process accountable for lower environmental impacts than the production of these products via an alternative route?," whereas the question "What impacts are caused by the production of Product X via the co-producing process" is modelled via substitution. Therefore, this issue is not discussed further in this paper.

With these issues in mind, this study intends to illustrate and discuss the effects of the following methodological aspects on the carbon footprint (global warming; GW) of polymers: (i) alternative formulas to handle the burden of the secondary raw material used as feedstock for bio-based plastics and the recyclability at EoL, (ii) fully and explicitly accounting for biogenic carbon and its dynamic cycle, and (iii) including LUC effects. Notice that all these methodological aspects are inextricably related to the handling of biogenic carbon. While the study largely focuses on the first of the three aspects, LUC and dynamic carbon accounting are also tackled to illustrate the full-extent of the consequences of biogenic carbon-related methodological choices on the results. As interest in bioplastics as a climate change mitigation strategy increases, it is important that the many lessons already learned from bioenergy LCA studies are translated to bioplastics research. Thus, the overarching goal of this study is to shed light on key methodological issues to provide an assessment guide for $\mathrm{C}$-footprint studies of bioplastics to complement or improve existing methods/frameworks.

To this end, we assess the environmental performance of a number of polymers produced from conventional fossil-based plastic versus the same polymers derived from alternative feedstock. For illustrative purposes, we consider two classes: polymers typically used for rigid packaging (i.e. single use) and polymers for automotive interior panels (i.e. durable). For the first class, we consider the following: high-density polyethylene (HDPE), 100\% recycled HDPE (R-HDPE), 100\% biobased polyethylene from sugarcane (B-HDPE), and $100 \%$ polylactic acid from organic waste (OW-PLA). For the second class, we consider polypropylene (PP), 100\% recycled polypropylene (R-PP), $100 \%$ biobased polybutylene succinate (B-PBS), and 100\% polylactic acid from maize (MA-PLA). Furthermore, we consider two alternative feedstocks for PLA (maize vs. organic municipal waste) in order to illustrate how the three methodological issues assessed affect the final results for different types of feedstock. For each case study, we assess four individual EoL scenarios: the average EU situation (best proxy for the year 2018) and the illustrative cases of $100 \%$ recycling, $100 \%$ incineration, and $100 \%$ landfilling. While we believe the approaches discussed herein are generally applicable, this study may not capture the specificities linked to biodegradable polymers or to the presence of additives.

\section{Method}

\subsection{Scope and functional unit}

The unit of analysis is $1 \mathrm{~kg}$ of polymer prepared for further use in the targeted application, i.e. rigid packaging or car interior panels. This is done for the purpose of simplification, despite the fact that the authors are well aware that different polymers may require slightly different amounts to fulfil specific product properties or services (for this, see Nessi et al. 2019). The method used for the GW impact assessment is the Myhre et al. (2013), as suggested in the Product Environmental Footprint ("Climate Change" indicator as in EF3.0; European Commission, 2013). The focus is on GW as this serves the purpose of illustrating and discussing the methodological issues mentioned earlier. A detailed description of the individual issues tackled and how they are addressed in this study is provided in Sects. 2.3, 2.4, and 2.5.

\subsection{System boundary and inventory}

The system boundary encompasses the life cycle activities undergone from the production of the feedstock material up to the End-of-Life treatment of the polymer, excluding the use phase, which is assumed to be the same for all polymers belonging to each group (Fig. 1). The stages are as follows: (I) feedstock supply including extraction, transport, and refining of crude oil and natural gas; crop cultivation and transport; collection, transport and sorting of recyclate; transportation of this feedstock to downstream conversion processes, e.g. naphtha cracking, sugarcane fermentation, and wet milling of starch crops; (II) polymer production including conversion of feedstock materials into the final polymer including any transport involved; (III) manufacture operations to prepare the polymer for further use in the sector of application alongside distribution, i.e. extrusion for rigid packaging and injection for panels; plus, distribution to retailer and final consumer; and (IV) End-of-Life including collection, sorting, recycling, incineration, or landfilling of the article after use, including any substituted process, e.g. virgin material or energy production. The electricity mix substituted by the energy generated through incineration was assumed to be equal to the residual $\mathrm{EU}$ electricity grid mix, composed by $57 \%$ fossil fuel, $37 \%$ nuclear, and $7 \%$ renewables (GW $0.14 \mathrm{~kg} \mathrm{CO}_{2}$-eq. $\mathrm{MJ}^{-1}$ electricity; Nessi et al. 2019). For heat, we used an EU average heat mix consisting of $42 \%$ natural gas, $31 \%$ hard coal, $22 \%$ biomass, and $5 \%$ heavy fuel oil ( $\mathrm{GW} 0.07 \mathrm{~kg} \mathrm{CO}_{2}$-eq. $\mathrm{MJ}^{-1}$ heat). Any multifunctional process was resolved following PEF guidelines. These prioritise subdivision and system expansion over allocation; yet, wherever an unambiguous market substitution 


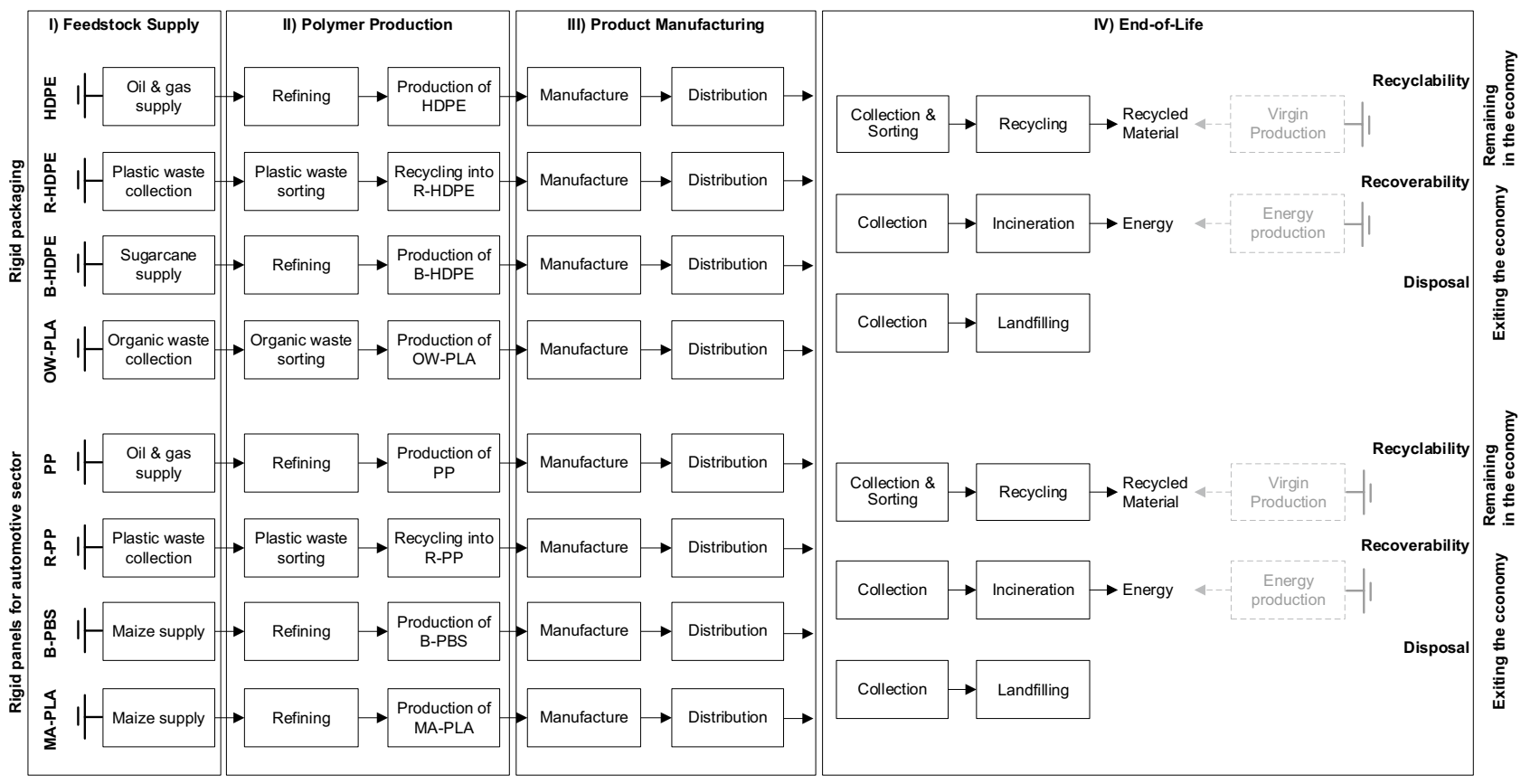

Fig. 1 Illustration of the scenarios investigated and of the related system boundaries. B-HDPE biobased high-density polyethylene, B-PBS biobased polybutylene succinate, HDPE high-density polyethylene,

could not be identified, economic allocation was applied instead. The EU-average EoL split for rigid packaging consists of $60 \%$ recycling, 21\% incineration, and 19\% landfilling, based on most recent data on PET bottles recycling (ICIS \& Petcore Europe, 2018) and management of plastic packaging waste in Europe (EUROSTAT, 2019). For car panels, the EoL consists of 97\% recycling, $2 \%$ incineration, and $1 \%$ landfilling (EUROSTAT, 2018). The life time of the products was assumed to 1 year for flexible packaging and 20 years for car panels. Notice that (i) landfilling here is modelled specifically for non-biodegradable plastics, i.e. carbon degradation is negligible; 9ii) recycling rates exclude possible future improvements following behavioural or technological changes; and (iii) the presence (and effects) of additives/contaminants in the recycling value chain is not addressed. The reader is referred to the Online Resource for a detailed description of the datasets used to represent the individual life cycle stages. Additional information may also be found in Nessi et al. (2019).

\subsection{Recycled content and recyclability}

\subsubsection{Background}

We define the recycled content $(R I)$ as the input of recycled material divided by the reference flow (i.e. the amount needed to fulfil the functional unit). We define the recycling output rate $(R 2)$ as the amount of recycled material supplied at the End-of-Life divided by the total waste generated after
MA-PLA polylactic acid from maize, OW-PLA polylactic acid from organic waste, PP polypropylene, R-HDPE recycled high-density polyethylene, R-PP recycled polypropylene

the use phase. $R 2$ shall therefore consider the inefficiencies in the collection, sorting and recycling (or reuse) processes. We call the fraction of the total generated waste that is collected and sent to energy recovery the energy recovery rate $(R 3)$. Several mathematical formulas have been proposed in the literature to address the contributions of the recycled content, recyclability, and recoverability on the overall impacts. Such formulas describe the life cycle environmental impact of a product from the provision of feedstock (i.e. virgin plus recycled content) to the EoL. While it is beyond the scope of this paper to describe the formulas in detail, in this study we refer to and use as a starting point two key studies that compared multiple existing formulas, i.e. Allacker et al. (2017) and Schrijvers et al. (2016). Allacker et al. (2017) proposed a formula as the most suitable for the European Commission Product Environmental Footprint (PEF). This approach models a 50:50 share of burdens and benefits from waste management between two subsequent life cycles and was the basis for the version presented in the PEF method (Zampori et al. 2016). Zampori et al. (2016) further introduced a market factor (here named $A^{\text {ef }}$ ) to replace the 50:50 share assumption of Allacker et al. (2017) to adjust for the market conditions of the recycling ( $A^{e f} 0$ for high quality and/or high demand, $A^{e f}$ 1 for low quality and/or low demand). The adapted formula of Zampori et al. is referred to as the circular footprint formula. A similar suggestion came from Schrijvers et al. (2016) that defined $A^{p}$ as the ratio between the market price 
of the recycled and the displaced virgin material $\left(A^{p} 1\right.$ when prices are the same, $A^{p} 0$ when the recycled material has a comparatively low value). The formula of Schrijvers et al. (2016) is updated in Schrijvers et al. (2020a, b), where $A^{p}$ 1 and $A^{p} \quad 0$ reflect high and low demand for the recycled material, respectively. Figure 2 introduces the conceptual framework for the three alternative approaches assessed in this study to account for the burden associated with the recycled content and the recyclability. The three formulas are presented in Table 1. In mathematical terms, for the way these factors are defined in Zampori et al. (2016) and Schrijvers et al. (2020a, b), when $A^{e f}$ tends to $1, A^{p}$ tends to 0 . Compared with the original formula from Allacker et al. (2017), the PEF formula presented by Zampori et al. (2016) has been simplified deleting the term $E_{d}{ }^{*}$ (avoided disposal of the material from which the recycled content is taken), see Table 1. This is also a substantial difference compared with the formula presented in Schrijvers et al. (2020a, b). The latter aims to reflect that the use of a recycled material that is already fully absorbed by the market diverts this material from other potential users that have to use an alternative, virgin, material instead. This leads not only to the induced production of this virgin material but also to other potential differences in the overall life cycle, such as differences in distribution, the use phase, and disposal. These additional differences between the expected life cycle and the substituted life cycle are also modelled in the formula (see $\Delta E^{o}$ for the recycled content and $\Delta E^{*}$ for the recyclability in Table 1).

\subsubsection{Approach taken}

We apply the formulas from Allacker et al. (2017), Schrijvers et al. (2020a, b), and Zampori et al. (2016) to the case studies to illustrate the effect of the different assumptions on the contributions of the recycled content, the recyclability, and the recoverability to the final GW result (Table 1). In particular, we focus on the influence of the terms related to disposal $\left(E_{d}, E_{d}{ }^{*}, E_{d}{ }^{o}\right)$, which represent a substantial difference between the three formulas analysed. Besides the effect of the formula selection, we also investigate the influence of the market parameter $A$ in the formula $\mathrm{I}$ and III (Schrijvers et al. 2020a, b and Zampori et al. 2016). We assess four scenario variants to illustrate the effects of varying the $A$ value. While a general description of the implications of these values is given in Table 2, the example of using OW-PLA instead of virgin HDPE is illustrated as follows. $\mathrm{A}=A^{p}=A^{e f}=0.5$ reflects the situation where the production of the OW-PLA is optimized for a defined demand. There is room for upscaling of the recycling process, although users of the recycled material could switch to an alternative material if prices were to increase (Ekvall,

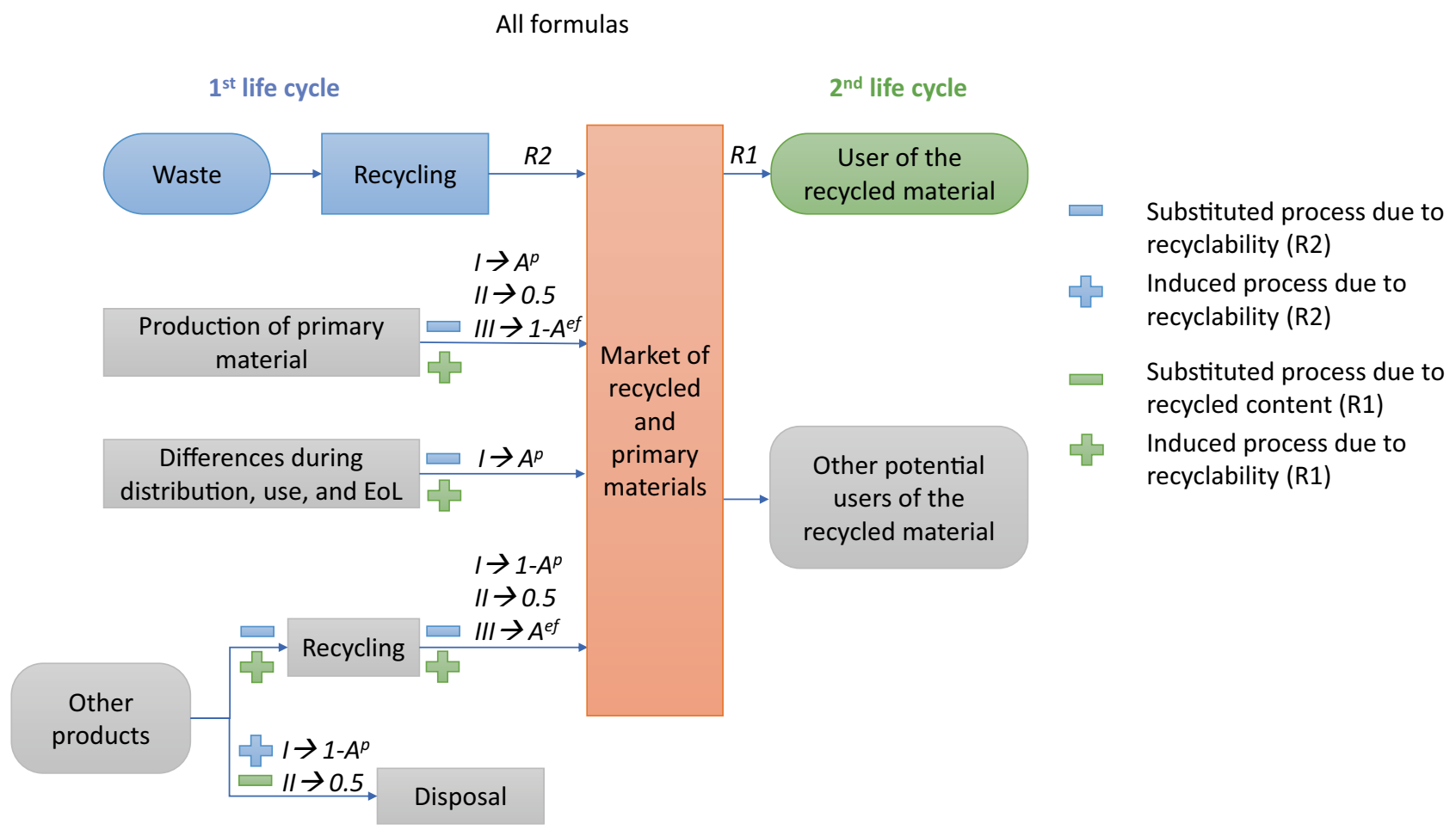

Fig. 2 Illustration of the modelling of recycling across the formulas I, II, and III (Schrijvers et al. 2020a, b; Allacker et al. 2017; Zampori et al. 2016). $A^{p}$ : market factor in Schrijvers et al. $(2016,2020 a, b) . A^{\text {eff }}$ market

factor in Zampori et al. (2016). EoL End-of-Life, R1 recycled content, R2 recycling output rate 
Table 1 Life cycle contributions as formulated in Schrijvers et al. (2020a, b), Allacker et al. (2017) and Zampori et al. (2016), indicated with I, II, and III respectively

\begin{tabular}{|c|c|c|c|c|c|}
\hline Eq & $\begin{array}{l}\text { Virgin content } \\
\text { contribution }\end{array}$ & Recycled content contribution & Recyclability contribution & $\begin{array}{l}\text { Recoverability } \\
\text { contribution }\end{array}$ & Disposal contribution \\
\hline I Equation 1 & $E_{v}(1-R 1)$ & $\begin{array}{l}R 1\left[\left(1-A^{p, o}\right)\left(E_{r}^{o}-E_{d}^{o}\right)\right. \\
\left.\quad-A^{p, o} \frac{Q^{o}}{Q_{v}^{o}}\left(\Delta E^{o}-E_{v}^{o}\right)\right]\end{array}$ & $\begin{array}{l}R 2\left[E_{r, r e c}-\left(1-A^{p, *}\right)\left(E_{r}^{*}-E_{d}^{*}\right)\right. \\
\left.\quad+A^{p, *} \frac{Q^{*}}{Q_{v}{ }^{*}}\left(\Delta E^{*}-E_{v}{ }^{*}\right)\right]\end{array}$ & $R 3\left(E_{e r}-C_{e r}\right)$ & $(1-R 2-R 3) E_{d}$ \\
\hline $\begin{array}{l}\text { II } \\
\text { Equation } 2\end{array}$ & $E_{v}\left(1-\frac{R 1}{2}\right)$ & $\frac{R 1}{2}\left(E_{r}^{o}-\frac{Q_{v}^{o}}{Q_{v}{ }^{o}} E_{v}^{o}-E_{d}^{o}\right)^{\top}$ & $\frac{R 2}{2}\left(E_{r}^{*}-\frac{Q_{v}}{Q_{v}^{*}} E_{v}^{*}+E_{d}\right)$ & $R 3\left(E_{e r}-C_{e r}\right)$ & $(1-R 2-R 3) E_{d}$ \\
\hline $\begin{array}{l}\text { III } \\
\text { Equation } 3\end{array}$ & $E_{v}(1-R 1)$ & $R 1 \cdot\left[A^{e f} E_{r}^{o}+\left(1-A^{e f}\right) \frac{Q^{o}}{Q_{v}^{o}} E_{v}^{o}\right]$ & $\left(1-A^{e f}\right) R 2\left(E_{r}^{*}-\frac{Q^{*}}{Q_{v}{ }^{*}} E_{v}^{*}\right)$ & $R 3\left(E_{e r}-C_{e r}\right)$ & $(1-R 2-R 3) E_{d}$ \\
\hline Term & \multicolumn{5}{|l|}{ Definition } \\
\hline$A^{e f}$ & \multicolumn{5}{|c|}{$\begin{array}{l}\text { Market conditions parameter used in } \operatorname{PEF}\left(A^{e f} 0 \text {, market for recyclables is high or high-quality recyclates; } A^{e f} 1 \text {, market for }\right. \\
\text { recyclables is low or low-quality recyclates })\end{array}$} \\
\hline$A^{p, o}$ & \multicolumn{5}{|c|}{ Market parameter for the recycled content. $A^{p, o} 1$, demand is high, $A^{p, o} 0$, demand is low } \\
\hline$A^{p, *}$ & \multicolumn{5}{|c|}{ Market parameter for the supplied recycled material. $A^{p, o} 1$, demand is high, $A^{p, o} 0$, demand is low } \\
\hline$C_{e r}$ & \multicolumn{5}{|c|}{ LCI of the substituted energy source } \\
\hline$E_{d}$ & \multicolumn{5}{|c|}{$\begin{array}{l}\text { LCI (per unit of analysis) arising from disposal of waste material at the EoL of the product analysed (e.g. landfilling, incinera- } \\
\text { tion, pyrolysis) }\end{array}$} \\
\hline$E_{d}^{o}$ & \multicolumn{5}{|c|}{$\begin{array}{l}\text { LCI (per unit of analysis) arising from the avoided disposal of waste material (e.g. landfilling, incineration, etc.) at the EoL of } \\
\text { the material where the recycled content is taken from }\end{array}$} \\
\hline$E_{d}^{*}$ & \multicolumn{5}{|c|}{$\begin{array}{l}\mathrm{LCI} \text { (per unit of analysis) arising from the induced disposal of waste material (e.g. landfilling, incineration, etc.) at the EoL of } \\
\text { recycled materials from other product value chains that are substituted by the recycled material }\end{array}$} \\
\hline$E_{r}^{o}$ & \multicolumn{5}{|c|}{$\begin{array}{l}\text { LCI (per unit of analysis) arising from the recycling process of the recycled content, including collection, sorting and transpor- } \\
\text { tation processes }\end{array}$} \\
\hline$E_{r}^{*}$ & \multicolumn{5}{|c|}{$\begin{array}{l}\text { LCI (per unit of analysis) arising from the recycling process at the End-of-Life stage of the displaced recycling process in other } \\
\text { value chains, including collection, sorting and transportation processes }\end{array}$} \\
\hline$E_{r, \text { rec }}$ & \multicolumn{5}{|c|}{ LCI (per unit of analysis) for the production of the supplied recycled material, including the disposal of losses during recycling } \\
\hline$E_{v}$ & \multicolumn{5}{|c|}{ LCI (per unit of analysis) arising from the acquisition and pre-processing of virgin material } \\
\hline$E_{v}^{o}$ & \multicolumn{5}{|c|}{$\begin{array}{l}\text { LCI (per unit of analysis) arising from the induced acquisition and pre-processing of the virgin material where the recycled } \\
\text { content is taken from }\end{array}$} \\
\hline$E_{v}^{*}$ & \multicolumn{5}{|c|}{$\begin{array}{l}\mathrm{LCI} \text { (per unit of analysis) arising from the acquisition and pre-processing of virgin material assumed to be substituted by the } \\
\text { recycled materials at EoL. If only closed-loop recycling takes place: } E_{V}{ }^{*}=E_{V}{ }^{\circ}\end{array}$} \\
\hline$Q^{o}$ & \multicolumn{5}{|c|}{ Quality of the secondary material used as input } \\
\hline$Q_{v}{ }^{o}$ & \multicolumn{5}{|c|}{ Quality of the primary material where the recycled content is taken from } \\
\hline$Q^{*}$ & \multicolumn{5}{|c|}{ Quality of the secondary material, i.e. the quality of the recycled or reused material at EoL } \\
\hline$Q_{v}{ }^{*}$ & \multicolumn{5}{|c|}{ Quality of the primary material substituted by the recycled material at EoL } \\
\hline Rl & \multicolumn{5}{|c|}{$\begin{array}{l}\text { Recycled (or reused) content of material, i.e. the proportion of material in the input to the production that has been recycled in } \\
\text { a previous system }(0 \leq R 1 \leq 1 \text {; dimensionless) }\end{array}$} \\
\hline$R 2$ & \multicolumn{5}{|c|}{$\begin{array}{l}\text { Recycling output rate, i.e. proportion of material in the product effectively recycled (or reused) into a subsequent system. } R 2 \\
\text { shall therefore consider the inefficiencies in the collection, sorting and recycling (or reuse) processes ( } 0 \leq R 2 \leq 1 \text {; dimension- } \\
\text { less) }\end{array}$} \\
\hline$R 3$ & \multicolumn{5}{|c|}{$\begin{array}{l}\text { Energy recovery rate, i.e. proportion of material in the product used for energy recovery (e.g. incineration with energy recov- } \\
\text { ery) at EoL }(0 \leq R 3 \leq 1 \text {; dimensionless) }\end{array}$} \\
\hline$\eta^{o}$ & \multicolumn{5}{|c|}{ Conversion efficiency of the waste into a recycled material that is used as recycled content } \\
\hline$\eta^{*}$ & \multicolumn{5}{|c|}{ Conversion efficiency of the End-of-Life waste into a recycled material that is produced at the end of life } \\
\hline$\Delta E^{o}$ & \multicolumn{5}{|c|}{$\begin{array}{l}\text { LCI due to additional (or decreased) downstream elementary flows in relation to use and disposal of recycled material, as com- } \\
\text { pared with the primary material substituted, by the alternative user of the demanded recycled material }\end{array}$} \\
\hline$\Delta E^{*}$ & \multicolumn{5}{|c|}{$\begin{array}{l}\text { LCI due to additional (or decreased) downstream elementary flows in relation to use and disposal of recycled material, as com- } \\
\text { pared with the primary material substituted, by the user of the supplied recycled material }\end{array}$} \\
\hline
\end{tabular}

2000), which is an effect that could be relevant in the short term. In a first scenario variant we set $\mathrm{A}=A^{p}=0\left(A^{\text {ef }} 1\right)$, implying that there is a very low demand for OW-PLA. Stimulating the demand for OW-PLA could avoid the food waste, which is used as feedstock, being disposed of as waste (here assumed to be incineration with energy recovery). This reflects the current EU situation, i.e. most of the organic waste is still being disposed of (or incinerated) and the use of the recycled material is occasional rather than mainstream. In the second variant $A=A^{p}=1\left(A^{e f} 0\right)$, all the available 


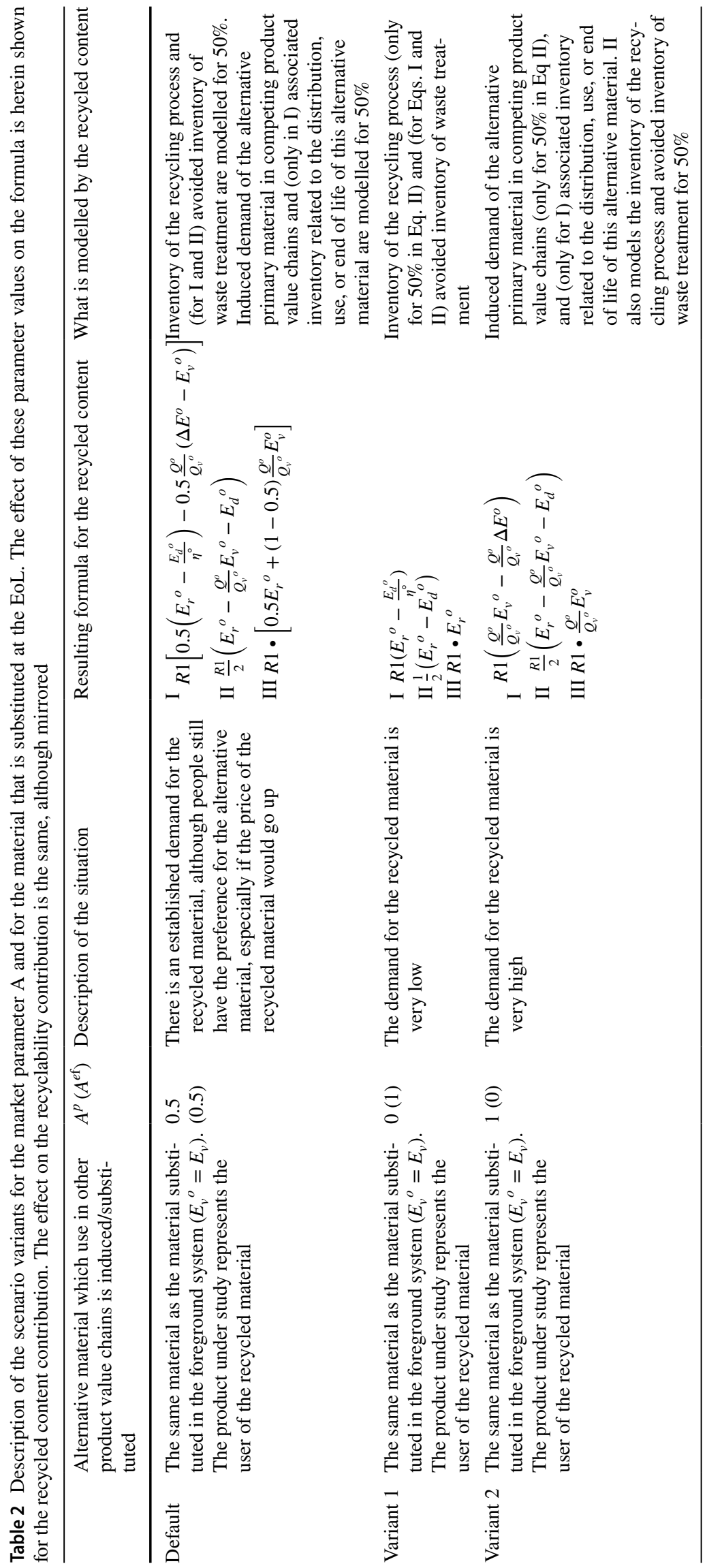


waste is exploited and the maximum amount of OW-PLA is used, and further upscaling of the recycling process is not possible due to a lack of available food waste.

\subsection{Biogenic carbon accounting}

\subsubsection{Background}

Bio-based products are seen as an opportunity to substitute finite fossil sources with renewable and carbon-neutral products, and as such are at the centre of the EU bioeconomy strategy (EU bioeconomy strategy, 2018). However, experience within the LCA community with bioenergy has shown that the climate change mitigation potential of biobased commodities cannot be taken for granted, but rather needs to be assessed with care (European Commission, 2019). Especially critical is the way in which biogenic carbon (biogenic C) emissions are calculated along the life cycle of the bio-based product. Agostini et al. (2020), for instance, show that 71 out the 100 most cited LCA papers on bioenergy have applied a carbon neutrality assumption, meaning that both the used bio-based product and the emitted $\mathrm{CO}_{2}$ at the end of life are considered to have zero effect on global warming. Through this assumption the LCA practitioner avoids accounting for the biogenic carbon cycle by assuming that the carbon emitted from biomass combustion or decomposition will be reabsorbed by the growing plants on a time scale significantly shorter than the relevant temporal scale of the analysis. However, the biogenic carbon neutrality assumption is often misleading as the dynamics of the biogenic $\mathrm{C}$ cycle may be significant in the short/medium term (Agostini et al. 2013). In order to avoid potential burden shifting along the temporal scale, a growing number of LCA studies have been accounting explicitly for the time-dependent impacts of biogenic $\mathrm{C}$ cycle for at least 10 years (e.g. Levasseur, 2010; Cherubini et al. 2011; Brandao et al. 2013; Giuntoli et al. 2016, Levasseur, 2016; UNEP-SETAC, 2016, Breton et al. 2018). When assessing the climate change impact of biobased products, the biogenic $\mathrm{C}$ cycle has a strong timedependent nature: the biomass is harvested and transformed into a product, and while the biogenic $\mathrm{C}$ is stored in the technosphere during the use phase of the bio-product, the biomass re-grows sequestering atmospheric $\mathrm{CO}_{2}$ through specific dynamic trajectories (i.e. annual crops will re-sequester harvested $\mathrm{CO}_{2}$ every year, while a forest stand will take decades to regrow). The way these phenomena are characterized differs across various studies, based on the choice of climate metrics (instantaneous vs. cumulative; Giuntoli et al. 2015), the choice of absolute or normalised metrics (Cherubini et al. 2013), the choice of reference system (Koponen et al. 2018), and the choice of temporal boundaries of the analysis (Brandao et al. 2013; Levasseur,
2016; Breton et al. 2018). While discussing all these aspects in details is beyond the scope of this paper, it is important to notice that no choice is right or wrong, but that any choice will embed value judgement, thus we transparently report our assumptions in the Online Resource.

Testifying to the complexity of the issue, no normative agreement on how to account for biogenic $\mathrm{C}$ in LCA exists yet. For instance, the CEN (2015) suggests two different approaches for forest $\mathrm{C}$-accounting: if the analysis is performed at landscape level, then a carbon neutrality assumption is advised, while a calculation of dynamic $\mathrm{C}$-cycle is recommended if the analysis is performed at stand level. Similarly, the BSI (2011) instructs that, where some or all removed carbon will not be emitted to the atmosphere within the 100-year assessment period, the portion of carbon not emitted to the atmosphere during that period shall be treated as permanently sequestered carbon. European Commission (2013) and (ISO, 2013), conversely, instruct the user to characterise all emissions and sequestration of biogenic $\mathrm{CO}_{2}$ with a GWP $=0$.

\subsubsection{Approach taken}

We consider the default choice of carbon neutrality (i.e. to characterize biogenic $\mathrm{C}$ sequestration and emissions with a GWP $=0$ ) to be equivalent to taking a long-term perspective (e.g. > 100 years) in which the impact of the biogenic $\mathrm{C}$ cycle is irrelevant compared with the impact of the permanent release of fossil $\mathrm{CO}_{2}$. However, we reckon that evaluating short-term climate impacts is essential to inform decisions on a temporal scale more in tune with the urgency required by the climate crisis. Therefore, similar to the method presented by Cherubini et al. (2011) and Guest et al. (2013), we provide GWP factors for biogenic $\mathrm{C}$ and for fossil $\mathrm{C}$ that take into account the effects of time. For biogenic C, we provide characterisation factors $\left(\mathrm{GWP}_{\mathrm{bio}}\right)$ valid for biomass feedstocks with different rotation periods as well as with two different EoL scenarios: (i) incineration after the use period and (ii) landfilling after the use period. Consistently, for the case of $100 \%$ recycling at EoL, we considered the credits from temporary biogenic $\mathrm{C}$ storage incurred by extending the lifetime of the material in the technosphere (one additional lifecycle). This corresponded to an additional 20 years for the case of car panels (in total 40 years). The $\mathrm{GWP}_{\text {bio }}$ factors range from net negative values to positive values (albeit still lower than 1). Consistently, we also provide $\mathrm{GWP}_{\text {fossil }}$ values that take into account the effect of delayed emissions of fossil C compared with an emission taking place at $t=0$. It should be noticed that there is a significant difference between the negative $\mathrm{GWP}_{\text {bio }}$ values assigned to biogenic $\mathrm{C}$ and the reduced 
positive values for fossil $\mathrm{CO}_{2}$. The former represents a credit for temporary storage in the technosphere, while the biomass is allowed to regrow, while the latter is a decreased burden for delayed emission with respect to the fixed time horizon chosen. Indeed, all the GWP values used are reported at a fixed time horizon of 100 years, as it is common practice for LCA. All details of the calculations performed are presented in the Online Resource. The values in Tables S7 and S8 (Online Resource) are used in the following sections to evaluate the impact of explicitly considering biogenic $\mathrm{C}$ flows and time-dependent dynamics. Notice that while we use a dynamic approach solely for biogenic $\mathrm{CO}_{2}$, biogenic $\mathrm{CH}_{4}$ is accounted for using the proper $\operatorname{GWP}(100)$ factors within the EF3.0 method. In the case of products with significant, time-dependent emission profiles of biogenic- $\mathrm{CH}_{4}$, such as it could be for the landfilling of biodegradable bioplastics, we recommend that a similar dynamic approach is also taken for biogenic $\mathrm{CH}_{4}$, as illustrated in Giuntoli et al. (2016). Notice also that credits from temporary storage/delayed emissions are shared between life cycles conforming to the formulas considered (Table 1), consistently with the other GHG emissions and in line with the recommendations from Finkbeiner et al. (2012).

\subsection{Land use changes}

\subsubsection{Background}

While dLUC refers to the changes occurring on the same land where the land use for the product under assessment takes place, iLUC refers to market-driven consequences incurred by the demand for land occurring in the first place (Schmidt et al. 2015; Valin et al. 2015). The point of departure for iLUC to occur is when arable land, already in use for cropping or grazing activities, is used for supplying the feedstock under assessment. The pre-condition for iLUC is that the global agricultural area is still expanding because of several confounding factors (such as increased population and GDP increase of some countries) and that its capacity is inherently limited/constrained (Schmidt et al. 2015). The main underlying postulate of iLUC is that this relative drop in availability is likely to cause a relative increase in agricultural prices, which in turn provides incentives to increase production elsewhere. This increase in production in principle can incur: (i) agricultural land expansion at the expenses of forest or grassland, (ii) production intensification, and (iii) crop-displacement mechanisms (reduced consumption). The latter is supported by some studies arguing that in the short-to-medium term not all of the displaced feedstock may need to be compensated by increased production as reduced consumption may also occur (e.g. Edwards et al. 2010). This hypothesis is however contradicted by other authors (e.g. Schmidt et al. 2015; Searchinger et al. 2015) arguing that this effect should not be included in LCAs, since it is the long-term effect of the demand that should guide decisions (Weidema et al. 2013). According to this and assuming no consumer's behavioural changes (e.g. diet), the supply of goods and services should be assumed to be fully elastic, i.e. an increase in demand is to be met by a corresponding $(1: 1)$ increase in supply.

\subsubsection{Approach taken}

For biobased polymers we assess the contribution of various LUCs emission factors on the Global Warming results. Most of the iLUC factors derived with global equilibrium models already include dLUC, i.e. changes in $\mathrm{C}$ stock are estimated not only for (additional) natural land clearing (e.g. forest, grassland, pasture, savannah) but also for cropland, as stressed in Valin et al. (2015). Therefore, in this study we opt not to distinguish between dLUC and iLUC and instead simply refer to LUC. We quantify the LUC contribution using three different LUC models available from the literature. The first is the biophysical model proposed by Schmidt et al. (2015) used as the default, the second builds on the LUC factors derived with an economic equilibrium model (Valin et al. 2015) and the third is a normative-based approach that applies the LUC factors suggested by European Parliament and Council of the European Union (2015) (annex V and VIII; also obtained through economic modelling). Among the three models, Valin et al. (2015) strives to include all C-stock changes due to the increased biomass demand, i.e. natural land clearing and cropland. The LUC GW contribution is calculated as follows: the specific land demand for crop production is converted into a demand per functional unit, based on the specific consumption of crop for polymer production ( $\mathrm{kg}$ crop $\mathrm{kg}^{-1}$ polymer, consistent with LCI modelling). The LUC GW contribution is finally calculated by multiplying the land demanded by the LUC GW emission factor obtained from the model chosen.

Along with the three LUC emission factors above, we also present the direct LUC contribution as quantified following the standard BSI (2011) complemented with BSI (2012) for illustrative purposes. The standard suggests the following approach to quantify dLUC: two main types of land transformation are considered, i.e. transformation from grassland and transformation from forest (to annual or perennial crop). The emissions arising from the product are assessed on the basis of the default land use change values provided in PAS 2050:2011 or using the relevant sections of the IPCC Guidelines for National Greenhouse Gas Inventories (IPCC, 2006) for countries and LUC types not covered by the former. 
GLOBAL WARMING

( $\mathrm{kg} \mathrm{CO}_{2}$-eq. $\mathrm{kg}^{-1}$ )

a)
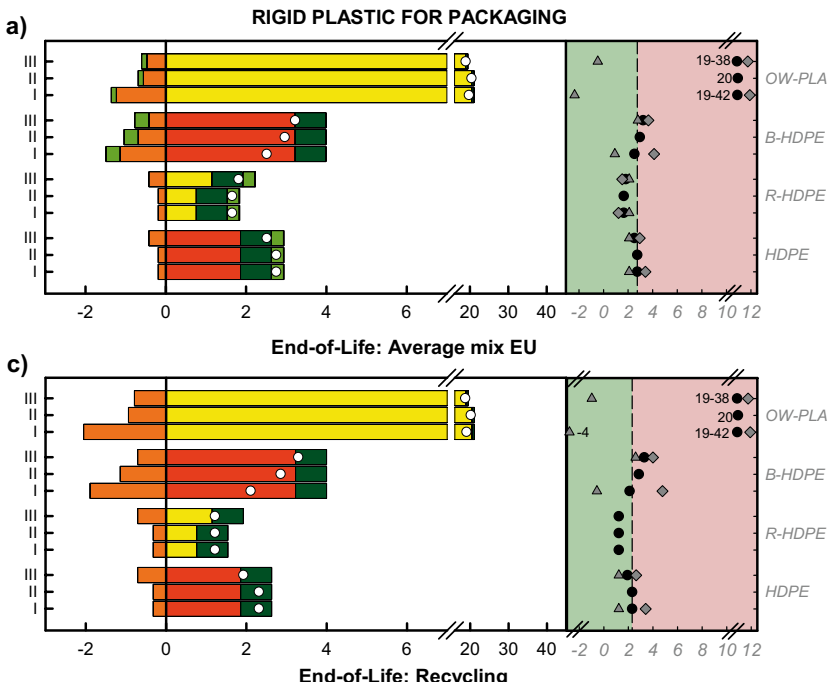

e)

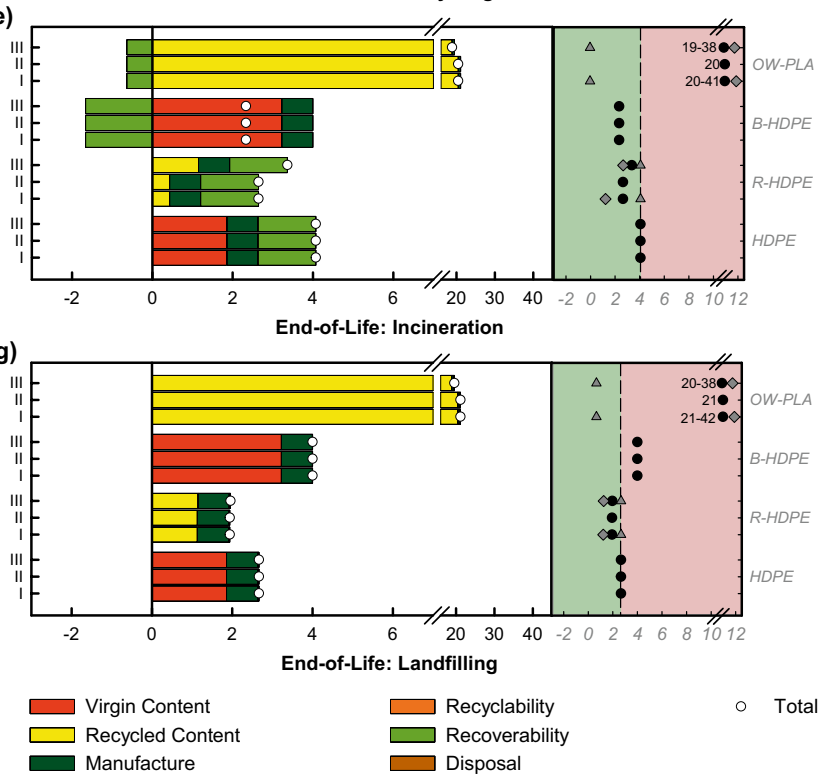

Fig. 3 Global warming impact for the polymers investigated, excluding LUCs and (biogenic) $\mathrm{C}$ dynamic effects. I, II, and III refer to the formula applied (Table 1). The left-hand chart illustrates the breakdown of the impact contributions; the right-hand side displays the total result alongside the results for the scenarios variants (high and low demand for recycling) when these do not overlap with the default assumptions (for comparison); the dashed line indicates the impact of the reference fossil product calculated with formula I with the default assumptions. Four individual End-of-Life framework scenarios are analysed (EU average, 100\% recycling, 100\% incineration, and 100\% landfilling). Virgin content: contribution associated with the primary

\section{Results and discussion}

We present the results in a sequential fashion: (i) we focus on recycled content and recyclability (Fig. 3; as default $A=0.5$, but we include scenario variants for

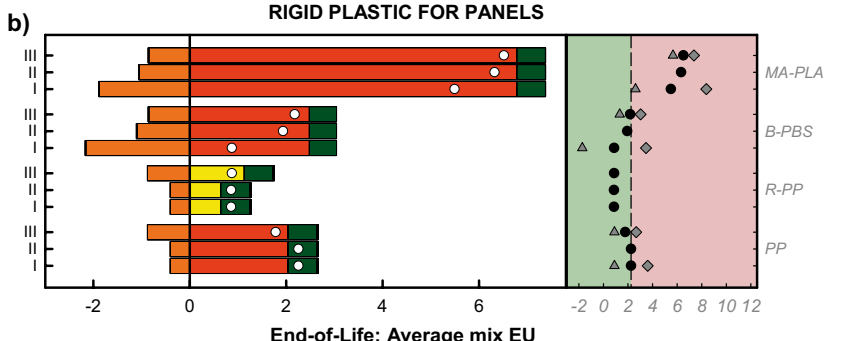

d)

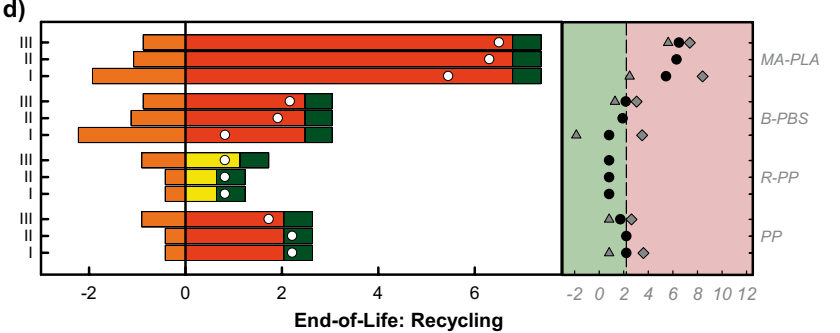

f)
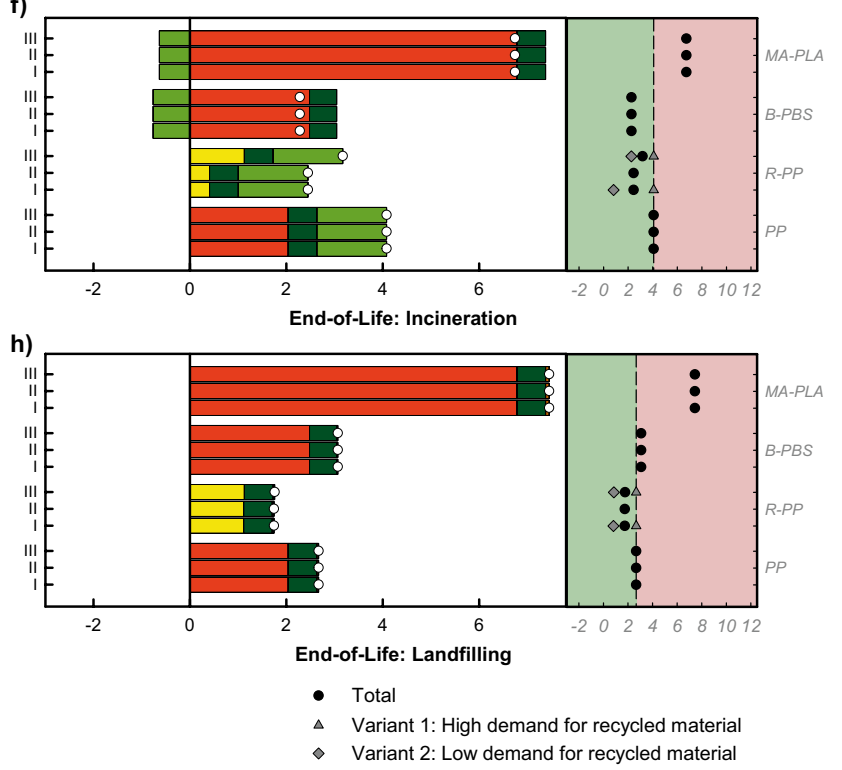

material used. Recycled content: contribution associated with the secondary material used. Manufacture: contribution of final conversion into packaging or panel. Recyclability: contribution of recycling and substitution of primary material. Recoverability: contribution from incineration with energy recovery and related substitution of market electricity and heat. Disposal: Contribution from landfilling. Total: total sum. B-HDPE biobased high-density polyethylene, B-PBS biobased polybutylene succinate, HDPE high-density polyethylene, MA-PLA polylactic acid from maize, OW-PLA polylactic acid from organic waste, PP polypropylene, R-HDPE recycled high-density polyethylene, R-PP recycled polypropylene

$A=0$ and $A=1$; LUC and biogenic $\mathrm{C}$ dynamics are not included assuming neutrality as the default); (ii) we add dynamic (for both biogenic and non-biogenic) carbon accounting and characterisation (Fig. 4); and (iii) we add the effects of land use change (Fig. 5; we include 
GLOBAL WARMING

( $\mathrm{kg} \mathrm{CO}_{2}$-eq. $\mathrm{kg}^{-1}$ )

a)
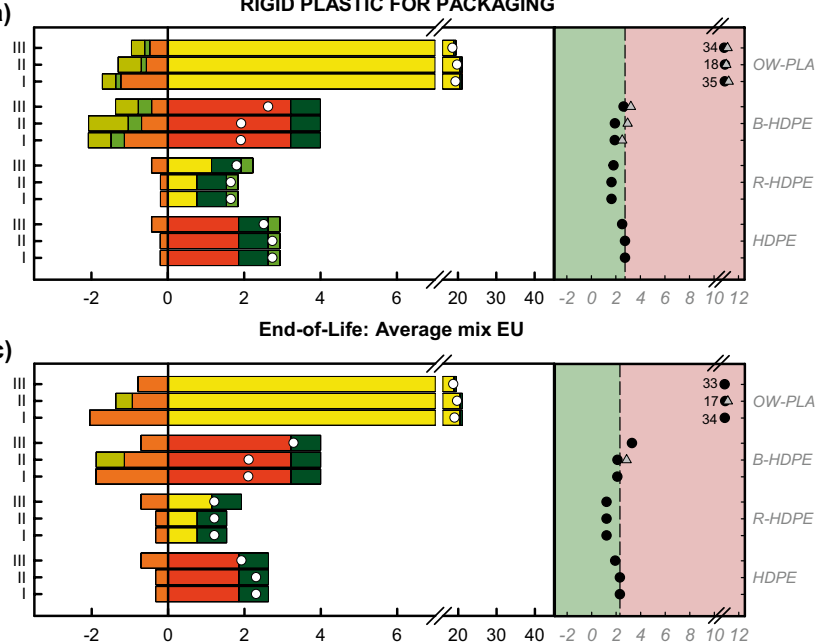

e)

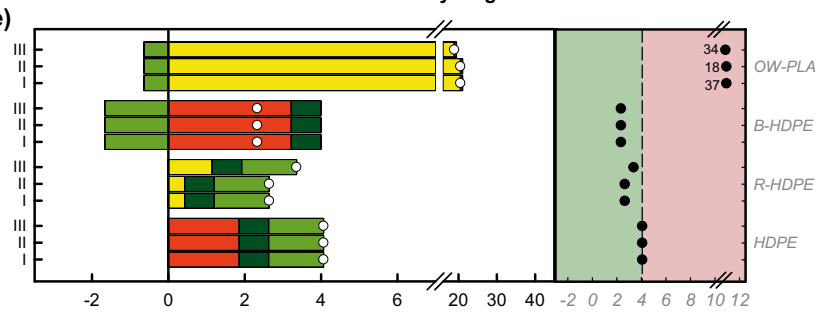

g)

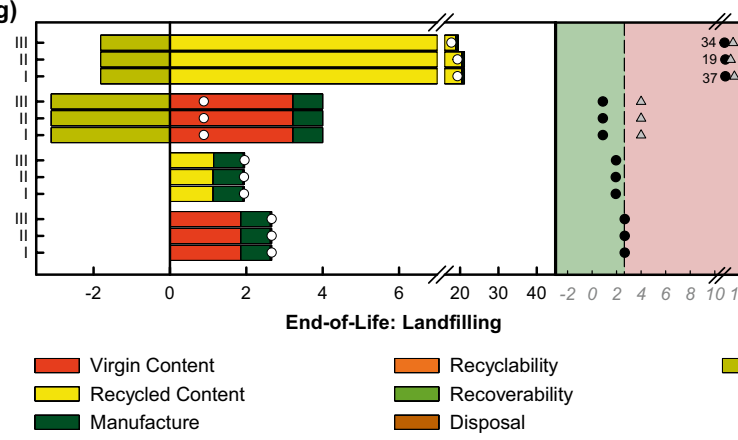

Fig. 4 Global warming impact for the polymers investigated, including (biogenic) $\mathrm{C}$ dynamic effects. I, II, and III refer to the formula applied (Table 1). The left-hand chart illustrates the breakdown of the impact contributions; the right-hand side displays the total result alongside the total results without applying dynamic carbon accounting when these do not overlap (for comparison); the dashed line indicates the impact of the reference fossil product calculated with formula I with the default assumptions. Four individual End-of-Life framework scenarios are analysed (EU average, 100\% recycling, $100 \%$ incineration, and $100 \%$ landfilling). Virgin content: contribution associated with the primary material used. Recycled content: contribution associated with the secondary material used. Manu-

a scenario variant; biogenic $\mathrm{C}$ dynamic effects are also included). Across all figures, negative values indicate lifecycle savings, while positive values represent impacts. The roman numbers I, II, and III refer to the formula applied (Table 1). b)

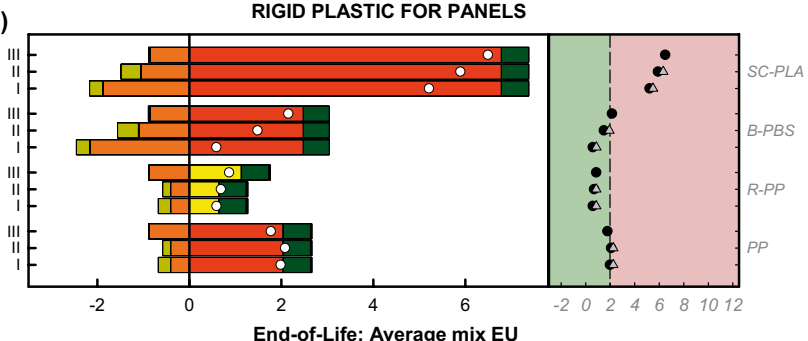

d)

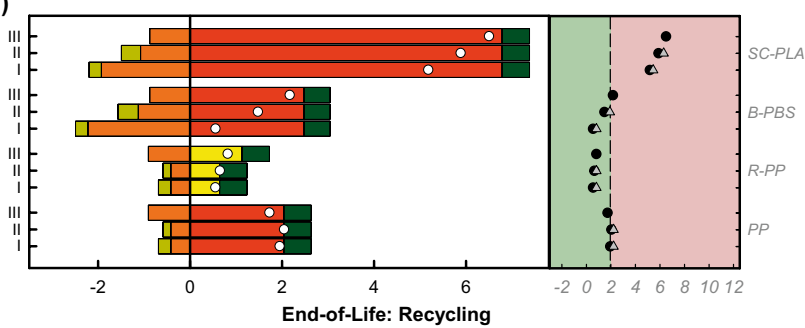

f)

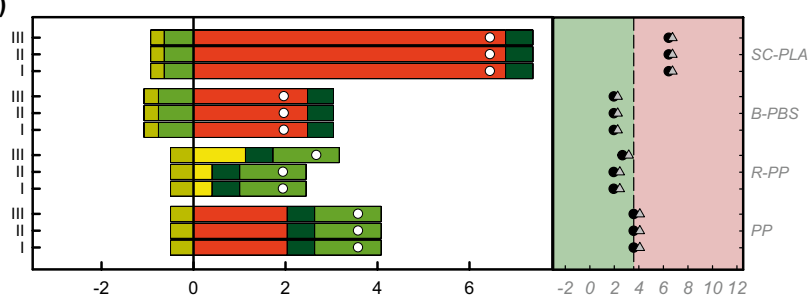

End-of-Life: Incineration

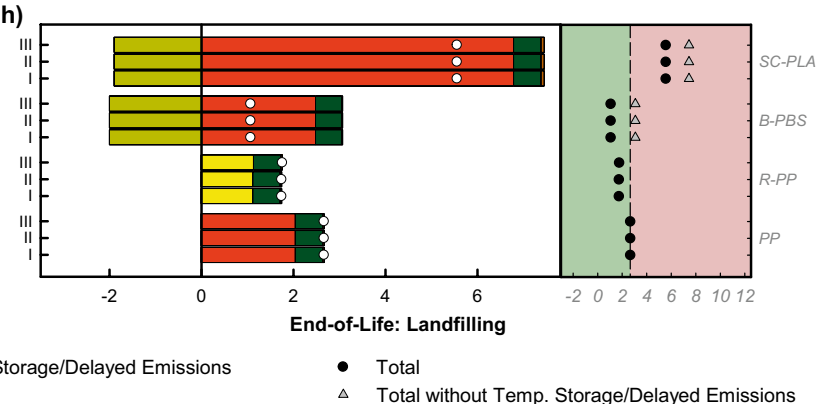

$\Delta$ Total without Temp. Storage/Delayed Emissions facture: contribution of final conversion into packaging or panel. Recyclability: contribution of recycling and substitution of primary material. Recoverability: contribution from incineration with energy recovery and related substitution of market electricity and heat. Disposal: Contribution from landfilling. Temp. storage/delayed emissions: contribution from temporary biogenic $\mathrm{C}$ storage or delayed fossil C emission. Total: total sum. B-HDPE biobased high-density polyethylene, B-PBS biobased polybutylene succinate, HDPE highdensity polyethylene, MA-PLA polylactic acid from maize, OW-PLA polylactic acid from organic waste, PP polypropylene, R-HDPE recycled high-density polyethylene, R-PP recycled polypropylene

\subsection{Recycled content and recyclability}

For rigid packaging, recycled HDPE shows the best performance on Global Warming regardless of the formula applied (Fig. 3), with the exception of the incineration 
GLOBAL WARMING

(kg CO

a)

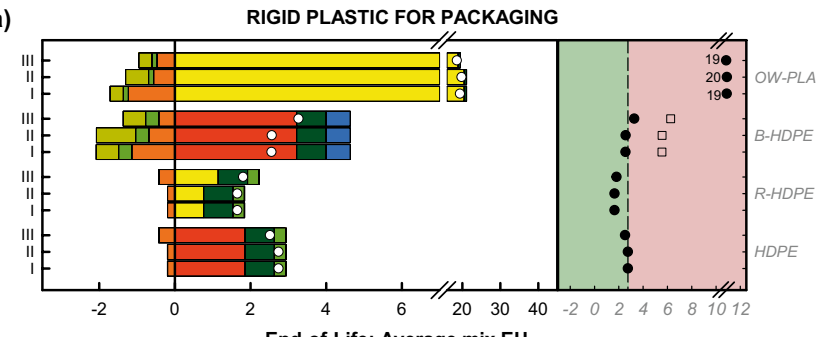

c)

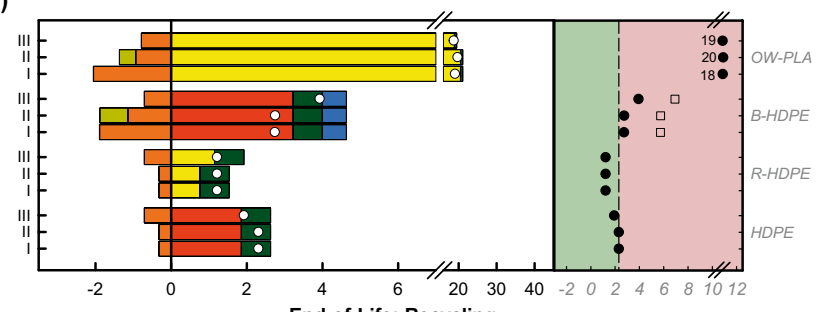

e)

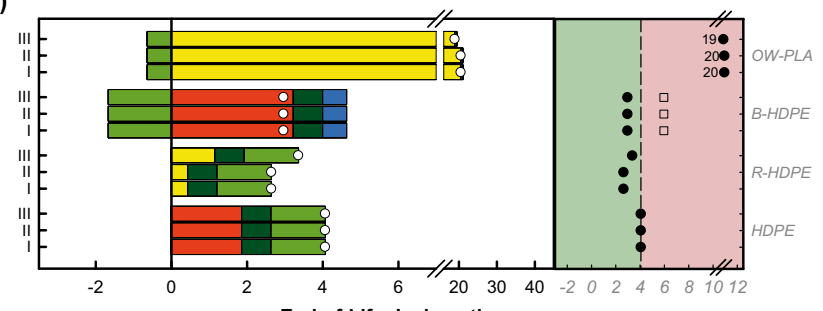

g)

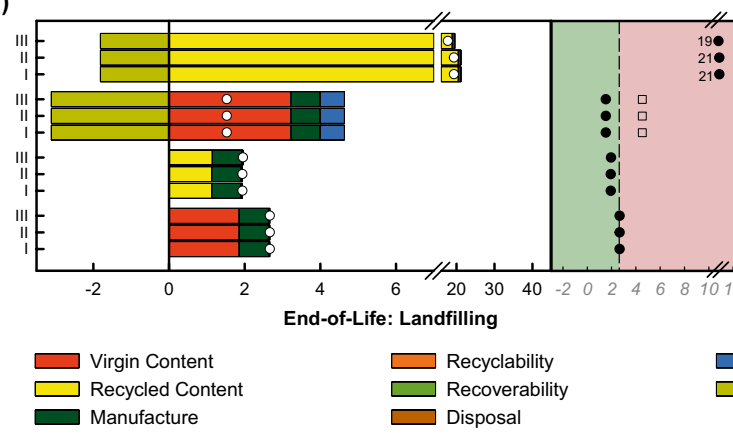

b)

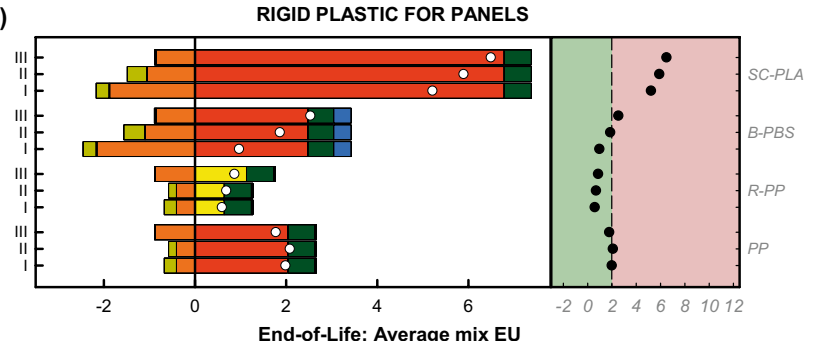

d)

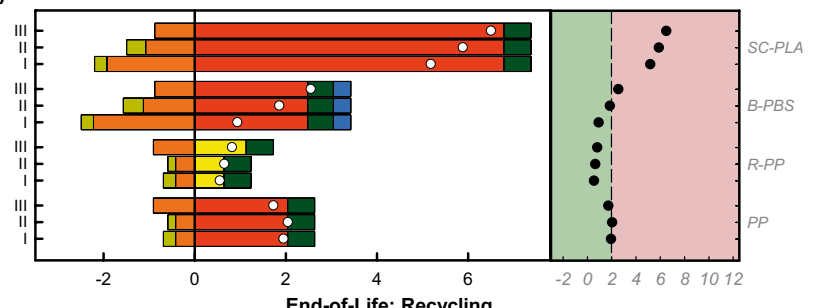

f)

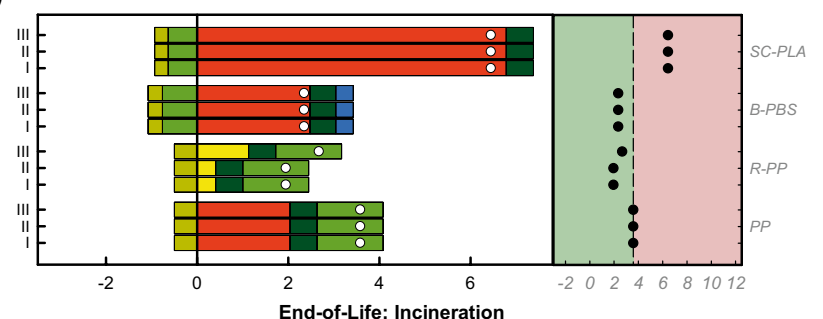

h)

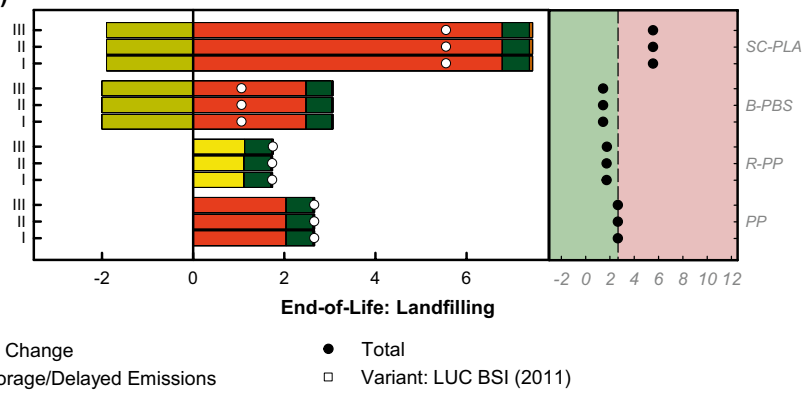

Fig. 5 Global warming impact for the polymers investigated, including LUCs and (biogenic) C dynamic effects. I, II, and III refer to the formula applied (Table 1). The left-hand chart illustrates the breakdown of the impact contributions; the right-hand side displays the total result alongside the total results when applying dLUC from BSI (2011) (for comparison); the dashed line indicates the impact of the reference fossil product calculated with formula I with the default assumptions. Four individual End-of-Life framework scenarios are analysed (EU average, 100\% recycling, 100\% incineration, and 100\% landfilling). Virgin content: contribution associated with the primary material used. Recycled content: contribution associated with the secondary material used. Manufacture: contribution of final conversion into packaging or panel. Recyclability: contribution of recycling and substitution of primary material. Recoverability: contribution from incineration with energy recovery and related substitution of market electricity and heat. Disposal: Contribution from landfilling. Temp. storage/delayed emissions: contribution from temporary biogenic $\mathrm{C}$ storage or delayed fossil $\mathrm{C}$ emission. LUC: contribution from land use changes. Total: total sum. B-HDPE biobased high-density polyethylene, B-PBS biobased polybutylene succinate, HDPE high-density polyethylene, MA-PLA polylactic acid from maize, OW-PLA polylactic acid from organic waste, PP polypropylene, R-HDPE recycled high-density polyethylene, R-PP recycled polypropylene

impact of 2.5-2.7 $\mathrm{kg} \mathrm{CO}_{2}$-eq. $\mathrm{kg}^{-1}$ for conventional HDPE. This impact decreases when assuming $100 \%$ recyclability owing to the increased benefits of recyclability. When assuming $100 \%$ incineration at EoL, instead, impacts are reduced only for B-HDPE thanks to larger contribution 
from recoverability. Notice that the impact of PLA from organic waste is mainly associated with the significant heat consumption for the processing and distillation required for lactic acid production, as explained elsewhere (Albizzati et al. 2020). For the case of interior car panels (Fig. 3b), $\mathrm{R}$-PP achieves the best performance $\left(0.9 \mathrm{~kg} \mathrm{CO}_{2}\right.$-eq. $\left.\mathrm{kg}^{-1}\right)$ regardless of the formula applied, followed by B-PBS (1.2-2.5 kg CO 2 -eq. $\mathrm{kg}^{-1}$ depending upon the formula applied), compared with an impact of $1.8-2.3 \mathrm{~kg} \mathrm{CO}_{2}$-eq. $\mathrm{kg}^{-1}$ for conventional PP, under the EU average EoL scenario for automotive waste and excluding LUCs and biogenic carbon effects. While these impact decreases when moving to full recycling at EoL, the difference between average EoL and 100\% recycling is negligible as current recycling rates are close to $100 \%$ (Fig. 3c, e).

Mathematical formulas I and II show comparable results for the fossil pathways, i.e. virgin and recycled plastics (see HDPE and R-HDPE or PP and R-PP; Fig. 3a-h). Formula III incurs lower GW for the virgin plastics when $100 \%$ recycled (see HDPE and PP; Fig. 3c, d; larger contribution from recyclability relative to formula I and II) and higher impacts for recycled plastics when $100 \%$ incinerated (see R-HDPE and R-PP; Fig. 3e, f). However, the three formulas differ significantly when focusing on the bioplastics in the recycling scenario. The differences observed relate to the contributions associated with recyclability and recycled content when waste is used as a feedstock. First of all, for both B-HDPE and PLA (both OW- and MA-), the contribution of the recyclability term is significantly larger in I than in III (I: Schrijvers et al. 2020a, b; III: Zampori et al. 2016) because the first formula includes the inventory of the differences between the final disposal of the recycled material and that of the corresponding avoided product $\left(\Delta E^{*}\right.$ in Table 1). This allows accounting for the different type of carbon in the recycled material (biogenic, with a GWP of zero) and the avoided material (fossil, GWP $=1$ ), which is not represented in formulas II and III (Allacker et al. 2017 and Zampori et al. 2016). In formula I, this increases the savings from recycling for biobased polymers when fossil polymers are replaced in the market.

Another difference between the three formulas is the contribution of the recycled content for the case of a bioplastic produced from organic waste feedstock, here represented by PLA from municipal organic waste. When applying I and II, the recycled content carries the burden of collection, recycling, and the contribution related to the avoided disposal of the material (Eqs. 1-2). Conventional disposal of the waste, as exemplified in this case study using average EU figures for the treatment of food waste, can be associated with net environmental savings, because of energy recovery from incineration. Therefore, when avoiding incineration to use the feedstock for plastic production, the contribution of the recycled content includes a term equal to the avoided benefits of such treatment. This is not represented in III (Eq. 3), which therefore tends to a "cutoff approach" where the burden associated with the inputfeedstock is disregarded and only collection and recycling are considered. This difference is more evident when a low demand for recycled material is assumed (see Fig. 3; variant 2). No significant differences are observed with respect to the contributions from recoverability and disposal across the three formulas investigated.

We further observe that the three formulas have a different degree of response to the variation of the parameter $A^{p} / A^{e f}$ (indicating the condition of the relevant recycling market). In general, for increased recycling at EoL, the savings are larger when a high demand for recyclate is assumed. Formula I is more sensitive than III because of the additional terms included $\left(\Delta E^{*}\right.$ and $\left.\Delta E^{o}\right)$, which in turn increases the range of variability of the results for biobased polymers (see results for B-HDPE and B-PBS in Fig. 3c, d).

\subsection{Dynamic characterisation of (biogenic) carbon emissions}

When dynamically characterising the emissions of biogenic $\mathrm{CO}_{2}$ associated with the product life cycle (i.e. uptake during biomass growth and release at EoL), the $\mathrm{GW}$ of the biopolymers decreases between 0.03 and $0.59 \mathrm{~kg} \mathrm{CO}_{2}$-eq. $\mathrm{kg}^{-1}$ using formula I and III and under the average EU EoL conditions (Fig. 5a, b). Using formula II, the decrease is larger (ca. $0.45-1 \mathrm{~kg} \mathrm{CO}_{2}$-eq. $\mathrm{kg}^{-1}$ ) because of the contribution from the term $E_{d}{ }^{o}$ in the recycled content contribution (see Eq. 2; Table 1). It is noticeable that the magnitude of the contribution associated with biogenic carbon emissions is comparable to that of LUC and compensates for that burden (see results for B-PBS, MA-PLA, and B-HDPE in Fig. 5 with LUC), excluding when LUC is calculated according to BSI (2011). Notice that the contribution is identical when EoL is $100 \%$ incineration or $100 \%$ recycling (Fig. 5d, f), as the timing of the delay is the same, i.e. the recycled biogenic carbon is credited only for one product life cycle. Notice also that this contribution from biogenic carbon emissions is not captured by formula III under increased recycling scenarios (see for example OW-PLA, MA-PLA, B-HDPE, and B-PBS in Fig. 5c, d) as the underlying equation does not retain the term representing the disposal of the recycled material (Eq. 3; Table 1). The effect of characterising biogenic carbon is, as expected, more pronounced when $100 \%$ landfilling is considered as the EoL owing to the fact that the biogenic carbon, largely non-degradable for the materials herein considered, is never released to the atmosphere while the biomass is regrowing; the results would be different for biodegradable bioplastics. When $100 \%$ landfilling is 
assumed as the EoL, accounting for biogenic $\mathrm{C}$ causes a saving of ca. $1.8-3 \mathrm{~kg} \mathrm{CO}_{2}$-eq. $\mathrm{kg}^{-1}$ depending upon the polymer considered (Fig. $5 \mathrm{~g}, \mathrm{~h}$ ).

Under these conditions, R-HDPE and B-PBS still remain the polymers with the lowest $\mathrm{C}$-footprint in their respective groups, but the footprint of all biobased pathways significantly decreases compared with the fossil counterpart because of accounting for the biogenic C. The magnitude of the credit from temporary storage of biogenic $\mathrm{C}$ and of the credit from delayed emission of fossil $\mathrm{C}$ is equal as we applied the $\mathrm{CO}_{2}$-timing consistently to both $\mathrm{C}$ pools (online resources). All in all, under the assumptions considered in this study, including the dynamic characterisation of biogenic $\mathrm{C}$ cycle reduces the impact of durable bioplastic (e.g. bio-PBS) by ca. $58 \%, 22 \%$, and $12 \%$, when the EoL is $100 \%$ landfilling, $100 \%$ recycling, and $100 \%$ incineration, respectively, relative to a carbon neutrality approach.

\subsection{Land use changes}

The LUC contribution to GW ranges from 0.29 (B-PBS) to 0.67 (B-HDPE) $\mathrm{kg} \mathrm{CO}$-eq. $\mathrm{kg}^{-1}$ polymer, when applying Schmidt et al. (2015), corresponding to about $15-30 \%$ of the total GW impact under the average EoL conditions (Fig. 4a, b and Table 3). These figures are comparable with Valin et al. (2015) and EU Parliament and Council of the EU (2015) (Table 3). We observe that the LUC factor by Schmidt et al. (2015) is higher than the alternatives when considering arable land for maize cultivation. This is due to how the individual LUC models have been developed. Most importantly, the LUC GW derived with the method BSI (2011) and (2012) is significantly larger and significantly affects the final GW result of the sugarcane derived B-HDPE pathway, overall corresponding to ca. $53-59 \%$ of the total GW impact under average EoL conditions (Fig. 4a; scenario variant: LUC BSI (2011)). This high contribution is a result of considering the historical deforestation patterns of the region where the sugarcane feedstock is sourced and then annualizing the $\mathrm{CO}_{2}$ emissions resulting from land clearing over a period of 20 years, and then distributing the resulting emission to each kilogram of biomass produced. In contrast to the alternative LUC models considered, this contribution does not aim to capture and reflect actual causal-effect relationships between the demand for a crop and the response of the land market. It aims to estimate a (direct) land-use change due to a potential future demand for crops by using historic patterns where eventual intensification or consumption reduction effects are not considered. All in all, under current EoL conditions, when both biogenic $\mathrm{C}$ emissions from uptake/release and from LUC are consistently addressed dynamically (e.g. using

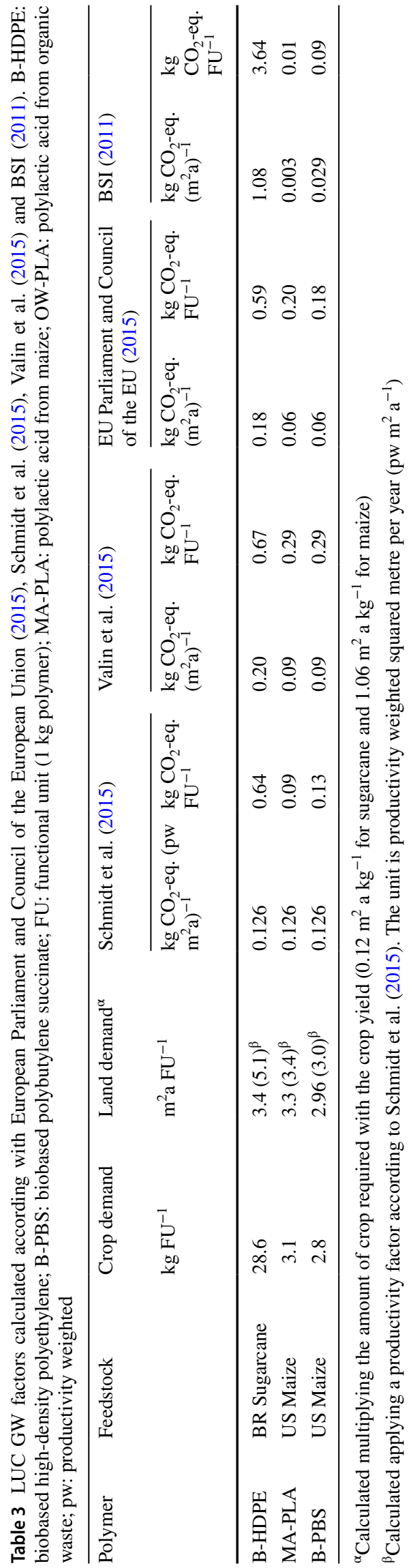


Schmidt et al. 2015), the impact of bioplastics decreases significantly, e.g. by $58 \%$ for B-HDPE (Fig. 5a; formula I) and $16 \%$ for B-PBS (Fig. 5 b; formula I) relative to disregarding biogenic $\mathrm{C}$ alongside applying historical dLUC factors. The decrease is least evident in formula III, as the underlying equation does not incorporate the final disposal of the recycled material or the difference between this and that of the material substituted (Eq. 3).

\subsection{Discussion}

This section provides a general discussion on the three methodological aspects tackled in this study with the aim of suggesting improvements to existing methods/frameworks for the handling of biogenic carbon. Note that, while the specific case studies investigated focused on bioplastics, many of the insights are applicable to biomaterials in general. With respect to the issue of feedstock recycling/recyclability, many of the anticipated climate change benefits of bioplastic (and biobased material in general) lie in biogenic, renewable carbon replacing fossil carbon. This study illustrates that some of the proposed life cycle formulas in their current form do not fully capture all of the effects associated with the renewable nature of the material when this is subject to recycling and used as a substitute for fossil-based materials. This can be corrected by including within the life cycle inventory the difference in emission flows arising from the End-of-Life treatment of the recycled and the market-substituted material, as proposed e.g. in Schrijvers et al. $(2020 \mathrm{a}, \mathrm{b})(\Delta \mathrm{E}$, Table 1$)$. While this aspect has been highlighted in previous studies (notably Finkbeiner et al. 2012), we still observe a lack of consistency and the need for corrections in some of the End-of-Life formulas proposed in the literature. We also highlight that when considering organic waste as feedstock, the formulas proposed in the literature respond differently. They range from including the alternative fate of the waste-feedstock, as in Schrijvers et al. (2020a, b) and Allacker et al. (2017), to a cut-off approach in Zampori et al. (2016). Modelling of avoided waste treatment has been widely applied in studies addressing the use of local organic wastes as feedstock for products, e.g. (Giuntoli et al. 2016; Hamelin et al. 2014; Styles et al. 2018; Tonini et al. 2019). This requires the identification of a likely alternative for the locally sourced organic waste which may be a challenge for a broader applicability in product LCA. Notwithstanding, we believe that especially when waste treatment is problematic, it is valuable to show the benefits of avoiding such waste treatment thanks to circular/innovative solutions via LCA.

A dynamic accounting of the biogenic $\mathrm{C}$ cycle provides emission credits for all EoL options and for eventual temporary storage within the technosphere, which further reduce the Global Warming impact of biobased polymers. While we do not claim to provide a simple solution to a much-debated issue in LCA such as biogenic $\mathrm{C}$ accounting (e.g. Brandao et al. 2013), our results clearly show that applying the carbon-neutrality approach in LCA might provide misleading results. Indeed, the best performance of bio-based materials is to actually have a net-zero impact on the climate (i.e. for annual crops), while any other biomass material with a longer growth period would cause greater climate impacts and would obtain fewer advantages compared with fossil-based alternatives in the short-medium term. As stressed by Agostini et al. (2020), we find that crucial information would be lost applying the carbonneutrality approach. Also, it should be noticed that our approach, similar to Cherubini et al. (2011), considers that biomass is replanted and allowed to regrow immediately after harvest, but any other situation would instead worsen the carbon accounting for biobased products.

The inclusion of LUC is often done through dLUC and, at times, iLUC factors. We observe that many of the available and most applied iLUC models in LCA ultimately provide LUC factors that already include dLUC. This applies particularly to values obtained from economic equilibrium models where the changes in $\mathrm{C}$ stock are estimated not only for forest land but also for cropland and pasture land, as clearly stressed for example in Valin et al. (2015). This, to some extent, also applies to the factors proposed in European Parliament and Council of the European Union (2015), which were derived from studies that applied global and partial equilibrium models. Therefore, as dLUC is already included in some popular datasets (e.g. ecoinvent 3.6, consequential version or PEF-datasets), additionally adding the iLUC factors derived from economic models theoretically results in a double-counting of dLUC emissions. We have simply reduced iLUC and dLUC to a single LUC factor, which is also proposed by Schmidt et al. (2015). In the context of a product LCA, this may be an effective solution to circumvent the unknown origin of the transformation (from which land use) and the application of historic land-use transformation patterns that may not be likely to reflect the cause-and-effect relation of demanding a certain feedstock today.

Besides the methodological aspects tackled, it should be borne in mind that the current mix of EoL options considered in this study may not adequately reflect what will apply in the future, especially for products with very long service lives, e.g. building or automotive materials. However, we have strived to cover all the relevant EoL options individually.

\section{Conclusion}

When calculating C-footprint of bioplastics and biomaterials, End-of-Life formulas can be improved by addition of corrective terms accounting for the relative 
difference in disposal impacts between the recycled and the market-substituted product (e.g. this may apply to formula III). This can have significant effects on the assessment of biobased materials. Time-dependent characterization of climate impacts allows a more complete interpretation of the impacts of the biogenic carbon cycle in the short/ medium term, providing useful insights for decision making. Inclusion of land use change emission factors derived from economic or biophysical models in addition to (direct) land use change emissions from historic clearing already embedded in commercial datasets may result in doublecounting and should be done carefully. All in all, we show that the way biogenic carbon is currently handled (from recyclability, to time-dependent accounting of biogenic $\mathrm{CO}_{2}$, to LUC) deserves significant attention for improvement in order for LCA to provide useful results in the context of bioeconomy climate implications. While we understand and consider the difficulties in finding normative consensus over these issues, we strongly encourage LCA practitioners to explore these different approaches when tackling biobased commodities and to either report results for multiple approaches in their sensitivity analysis, or to transparently declare why one approach has been chosen.

Supplementary Information The online version contains supplementary material available at (https://doi.org/10.1007/s11367-020-01853-2).

Acknowledgements We are grateful to the European Commission's DG GROW for providing funding for this study.

\section{Compliance with ethical standards}

Disclaimer The views expressed are purely those of the authors and may not in any circumstances be regarded as stating an official position of the European Commission.

Open Access This article is licensed under a Creative Commons Attribution 4.0 International License, which permits use, sharing, adaptation, distribution and reproduction in any medium or format, as long as you give appropriate credit to the original author(s) and the source, provide a link to the Creative Commons licence, and indicate if changes were made. The images or other third party material in this article are included in the article's Creative Commons licence, unless indicated otherwise in a credit line to the material. If material is not included in the article's Creative Commons licence and your intended use is not permitted by statutory regulation or exceeds the permitted use, you will need to obtain permission directly from the copyright holder. To view a copy of this licence, visit http://creativecommons. org/licenses/by/4.0/.

\section{References}

Agostini A, Giuntoli J, Boulamanti A (2013) Carbon accounting of forest bioenergy. JRC Technical Report. https://doi. org/10.2788/29442
Agostini A, Giuntoli J, Marelli L, Amaducci S (2020) Flaws in the interpretation phase of bioenergy LCA fuel the debate and mislead policymakers. Int J Life Cycle Assess 25(1):17-35. https://doi. org/10.1007/s11367-019-01654-2

Albizzati PF, Tonini D, Astrup TF et al (2020). Life cycle assessment and costing of high-value products from food waste: animal feed; lactic, polylactic, and succinic acid. Scie Total Environ

Allacker K, Mathieux F, Manfredi S, Pelletier N, De Camillis C, Ardente F, Pant R (2014) Allocation solutions for secondary material production and end of life recovery: proposals for product policy initiatives. Resour Conserv Recycl 88:1-12. https://doi. org/10.1016/j.resconrec.2014.03.016

Allacker K, Mathieux F, Pennington D, Pant R (2017) The search for an appropriate end-of-life formula for the purpose of the European Commission Environmental Footprint initiative. Int J Life Cycle Assess 22(9):1441-1458. https://doi.org/10.1007/ s11367-016-1244-0

Brandão M, Levasseur A, Kirschbaum MUF, Weidema BP, Cowie AL, Jørgensen SV, Hauschild MZ, Pennington DW, Chomkhamsri $\mathrm{K}$ (2013) Key issues and options in accounting for carbon sequestration and temporary storage in life cycle assessment and carbon footprinting. Int. J. Life Cycle Assess. 18:230-240. https:// doi.org/10.1007/s11367-012-0451-6

Breton C, Blanchet P, Amor B, Beauregard R, Chang WS (2018) Assessing the climate change impacts of biogenic carbon in buildings: A critical review of two main dynamic approaches. Sustain. 10. https://doi.org/10.3390/su10062020

BSI (2011) PAS 2050:2011. Specification for the assessment of the life cycle greenhouse gas emissions of goods and services. In October. ISBN 9780580713828 ICS 13.310; 91.190

BSI (2012) PAS 2050-1:2012. Assessment of life cycle greenhouse gas emissions from horticultural products

CEN (2015) NEN-EN 16760. Bio-based products-life cycle assessment

Cherubini F, Bright RM, Strømman AH (2013) Global climate impacts of forest bioenergy: What, when and how to measure? Environ. Res. Lett. 8:12. https://doi.org/10.1088/1748-9326/8/1/014049

Cherubini F, Huijbregts M, Kindermann G, Van Zelm R, Van Der Velde M, Stadler K, Strømman AH (2016) Global spatially explicit CO2emission metrics for forest bioenergy. Scie Rep. 6(July 2015) 1-12 https://doi.org/10.1038/srep20186

Cherubini F, Peters GP, Berntsen T, Strømman AH, Hertwich E (2011) $\mathrm{CO}_{2}$ emissions from biomass combustion for bioenergy: atmospheric decay and contribution to global warming. GCB Bioenergy 3(5):413-426. https://doi.org/10.1111/ j.1757-1707.2011.01102.x

Edwards R, Mulligan D, Marelli L et al (2010) Indirect land use change from increased biofuels demand. Comparison of models and results for marginal biofuels production from different feedstocks. In Joint Research Center of the EU (JRC): Ispra, Italy: Vol. EUR 24485. European Commission Joint Research Centre. http:// www.eac-quality.net/fileadmin/eac_quality/user_documents/ 3_pdf/Indirect_land_use_change_from_increased_biofuels_ demand_-_Comparison_of_models.pdf

Ekvall T (2000) A market-based approach to allocation at open-loop recycling. Resour Conserv Recycl 29(1-2):91-109. https://doi. org/10.1016/S0921-3449(99)00057-9

European Commission (2013) Recommendation 2013/179/EU on the use of common methods to measure and communicate the life cycle environmental performance of products and organisations. Off J Eur Union. L 124, 210. https://doi.org/10.3000/19770 677.L_2013.124.eng

European Commission (2019) Brief on the use of life cycle assessment ( LCA ) to evaluate environmental impacts of the bioeconomy EU publication (Issue May) https://doi.org/10.2760/90611006. Environmental Management-Life Cycle Assessment-Requirements and Guidelines: Vol. 1st ed 
European Parliament and Council of the European Union (2015) Directive (EU) 2015/1513 of the European Parliament and of the Council of 9 September 2015 amending Directive 98/70/EC relating to the quality of petrol and diesel fuels and amending Directive 2009/28/EC on the promotion of the use of energy from renewabl. https://eur-lex.europa.eu/legal-content/EN/ $\mathrm{TXT} /$ ?uri=CELEX\%3A32015L1513

Eurostat (2018) End-of-Life vehicles by waste management operations - detailed data. [online]. Available at: http://appsso. eurostat.ec.europa.eu/nui/show.do?dataset=env_waselv\& lang=en Accessed 5 Nov 2020

Eurostat (2019) Packaging waste by waste management operations and waste flow [env_waspac]. Available at: https://appsso. eurostat.ec.europa.eu/nui/show.do?dataset=env_waspac\& lang=en Accessed 5 Nov 2020

Finkbeiner M, Neugebauer S, Berger M (2012) Carbon footprint of recycled biogenic products: the challenge of modelling $\mathrm{CO} 2$ removal credits. Int J Sustain Eng. https://doi.org/10.1080/19397038. 2012.663414

Giuntoli J, Caserini S, Marelli L, Baxter D, Agostini A (2015) Domestic heating from forest logging residues: environmental risks and benefits. J Clean Prod 99:206-216

Giuntoli J, Agostini A, Caserini S, Lugato E, Baxter D, Marelli L (2016) Climate change impacts of power generation from residual biomass. Biomass Bioenerg 89:146-158. https://doi. org/10.1016/j.biombioe.2016.02.024

Guest G, Bright RM, Cherubini F, Strømman AH (2013) Consistent quantification of climate impacts due to biogenic carbon storage across a range of bio-product systems. Environ Impact Assess Rev 43:21-30. https://doi.org/10.1016/j.eiar.2013.05.002

Hamelin L, Naroznova I, Wenzel H (2014) Environmental consequences of different carbon alternatives for increased manure-based biogas. Appl Energy 114, 774-782. https://doi. org/10.1016/j.apenergy.2013.09.033

ICIS \& Petcore Europe (2018) Annual Survey on the European PET Recycling Industry 2017. Available at: https://petcore-europe. prezly.com/2017-surveyon-european-pet- recycle-industry-582-of-pet-bottles-collected\#

IPCC (2006). 2006 IPCC Guidelines for National Greenhouse Gas Inventories; Volume 4. Agriculture, Forestry and Other Land Use. Available at: https://www.ipcenggip.iges.or.jp/public/2006gl/vol4. html (accessed December 2020).

ISO (2006) ISO14040 Environmental Management-Life Cycle Assessment Requirements and Guidelines: Vol. 1st ed

ISO (2013) ISO 14067 Greenhouse gases - Carbon footprint of products - Requirements and guidelines for quantification and communication (Vol. 2013)

Koponen K, Soimakallio S, Kline KL, Cowie A, Brandão M (2018) Quantifying the climate effects of bioenergy - Choice of reference system. Renew. Sustain. Energy Rev. 81:2271-2280. https://doi. org/10.1016/j.rser.2017.05.292

Levasseur A, Cavalett O, Fuglestvedt JS, Gasser T, Johansson DJA, Jørgensen SV, Raugei M, Reisinger A, Schivley G, Strømman A, Tanaka K, Cherubini F (2016) Enhancing life cycle impact assessment from climate science: review of recent findings and recommendations for application to LCA. Ecol Ind 71:163-174. https://doi.org/10.1016/j.ecolind.2016.06.049

Levasseur A, Lesage P, Margni M, Deschěnes L, Samson R (2010) Considering time in LCA: Dynamic LCA and its application to global warming impact assessments. Environ. Sci. Technol. 44:3169-3174. https://doi.org/10.1021/es9030003

Myhre G, Shindell D, Bréon FM, Collins W, Fuglestvedt J, Huang J, Koch D, Lamarque JF, Lee D, Mendoza B, Nakajima T, Robock A, Stephens G, Takemura T, Zhang H (2013) Anthropogenic and natural radiative forcing. In: Climate Change 2. Cambridge
University Press, Cambridge, United Kingdomand New York, NY, USA. Park, S., 2018. Factors influencing

Nessi S, Bulgheroni C, Konti A, Sinkko T, Tonini D, Pant R (2019) Environmental sustainability assessment comparing through the means of lifecycle assessment the potential environmental impacts of the use of alternative feedstock (biomass, recycled plastics, $\mathrm{CO} 2$ ) for plastic articles in comparison to using current feeds. In European Commission -- Joint Research Centre -- Institute for Environment and Sustainability (Ed.), JRC Technical Reports. European Commission

Rossi V, Cleeve-Edwards N, Lundquist L, Schenker U, Dubois C, Humbert S, Jolliet O (2015) Life cycle assessment of end-oflife options for two biodegradable packaging materials: sound application of the European waste hierarchy. Journal of Cleaner Production 86:132-145. https://doi.org/10.1016/j.jclepro. 2014.08.049

Schmidt JH, Weidema BP, Brandao M (2015) A framework for modelling indirect land use changes in Life Cycle Assessment. J Cleaner Prod http://dx

Schrijvers DL, Loubet P, Sonnemann G (2016) Developing a systematic framework for consistent allocation in LCA https:// doi.org/10.1007/s11367-016-1063-3

Schrijvers DL, Loubet P, Sonnemann G (2020) Is the Circular Footprint Formula of the Product Environmental Footprint Guide consequential? A comparison against a systematized approach for consequential LCA. Submitted Journal of Cleaner Production

Schrijvers D, Loubet P, Sonnemann G (2020) Archetypes of goal and scope definitions for consistent allocation in LCA. Sustainability 12:5587. https://doi.org/10.3390/su12145587

Searchinger T, Edwards R, Mulligan D, Heimlich R, Plevin R (2015) Do biofuel policies seek to cut emissions by cutting food? Science 347(6229):1420-1422. https://doi.org/10.1126/science.1261221

Styles D, Adams P, Thelin G, Vaneeckhaute C, Chadwick D, Withers PJA (2018) Life cycle assessment of biofertilizer production and use compared with conventional liquid digestate management. Environ Sci Technol 52(13):7468-7476. https://doi.org/10.1021/ acs.est.8b01619

Tonini D, Saveyn HGM, Huygens D (2019) Environmental and health co-benefits for advanced phosphorus recovery. Nature Sustainability 2(11):1051-1061. https://doi.org/10.1038/s41893-019-0416-x

UNEP/SETAC (2016) Global Guidance for Life Cycle Impact Assessment Indicators. Volume 1.

Valin, H, Peters D, van den Berg M, Frank S, Havlik, P, Forsell N, Hamelinck C (2015) The land use change impact of biofuels consumed in the EU Quantification of area and The land use change impact of biofuels consumed in the EU Quantification of area and greenhouse gas impacts

Walker S, Rothman R (2020) Life cycle assessment of bio-based and fossil-based plastic: a review. J Clean Prod 261:121158. https:// doi.org/10.1016/j.jclepro.2020.121158

Weidema BP, Bauer C, Hischier R, Mutel C, Nemecek T, Reinhard J, Vadenbo CO, Wernet G (2013). The ecoinvent database: overview and methodology, Data quality guideline for the ecoinvent database version 3

World Economic Forum, Foundation EMM (2016) The new plastics economy rethinking the future of plastics. World Economic Forum. https://doi.org/10.4324/9780203965450

Zampori L, Pant R, Schau EM, De Schrijver A, Galatola M (2016). Circular Footprint Formula. October, 1-19.

Publisher's Note Springer Nature remains neutral with regard to jurisdictional claims in published maps and institutional affiliations. 